\title{
CAMPANAS Y CAMPANEROS: EL TALLER DE FUNDICIÓN DEL SIGLO XVIII DE LA ERMITA DE VERA CRUZ DE FRANDOVÍNEZ (BURGOS)
}

\begin{abstract}
POR
CARMEN ALONSO FERNÁNDEZ

Arqueóloga. Directora Técnica de Cronos S.C. Arqueología y Patrimonio

\section{RESUMEN}

Los resultados obtenidos en la excavación arqueológica realizada en la antigua ermita de la Vera Cruz de Frandovínez (Burgos), en concreto los relacionados con un taller de fundición de campanas del siglo XVIII, constituyen un importante avance en el conocimiento de este tipo de elementos del patrimonio histórico industrial, ya que de manera excepcional han sido documentadas la totalidad de las estructuras integrantes del taller. Por otro lado, la documentación existente de 1788, ha permitido indagar en aspectos relacionados con la contratación de la obra, el montante económico y los diferentes oficios que participaron en la empresa.
\end{abstract}

\section{PALABRAS CLAVE}

Fundición; campanas; foso de moldeo y función; horno de reverbero; excavación arqueológica.

\section{BELL AND RINGERS: THE BELL FOUNDRY XVIII CENTURY OF SHRINE VERA CRUZ FROM FRANDOVÍNEZ (BURGOS)}

\section{ABSTRACT}

The results achieved in the archaeological excavation at the ancient shrine of the Vera Cruz of Frandovínez (Burgos), more specifically those related to a bell foundry of the 18th century, represents an important step forward in the knowledge of this kind of elements of the industrial historical heritage, since, exceptionally, all the structures of the foundry have been documented. Furthermore, the existing documentation 
dated in 1788, has made possible investigating aspects of the work contract, the economic amount, and different artisan guilds that participated in the work.

\section{KEY WORDS}

Foundry; bells; casting pit and function; reverberatory furnace; archaeological excavation.

$\begin{array}{ll}\text { Recibido/Received } & 30-09-2013 \\ \text { Aceptado/Accepted } & 17-02-2014\end{array}$

\section{INTRODUCCIÓN}

La localidad de Frandovínez está emplazada en la comarca natural y agraria del Valle del Arlanzón, en el sector central de la provincia de Burgos y próxima a su capital (Fig. 1). Durante los trabajos de excavación arqueológica realizados en 2010 en el solar de la antigua ermita de la Vera Cruz $^{1}$ salieron a la luz las evidencias de un taller de fundición de campanas del siglo XVIII excavadas en el subsuelo; oportunidad excepcional para documentar en su totalidad las estructuras integrantes de un obrador de estas características, constituido por el foso de moldeo y fundición de tres campanas y por dos hornos de reverbero. Los restos exhumados son relevantes a nivel peninsular, ya que rara vez ha sido posible identificar y documentar mediante procedimientos arqueológicos la totalidad de las estructuras integrantes del proceso, incluidos los hornos.

A esta circunstancia se suma que existe constatación documental de la fecha de fundición de las campanas -1788-, así como una relación detallada del gasto que se derivó de su fabricación, acorde con la cronología de los restos cerámicos recuperados durante la excavación loza y cerámica común vidriada- que desde el punto de vista estratigráfico determinan la existencia de un único evento de amortización. Además, la revisión de los libros de fábrica de la iglesia parroquial de San Miguel, único registro documental encontrado alusivo a

${ }^{1}$ El solar de la antigua ermita de la Veracruz, incluido en el Inventario Arqueológico de Castilla y León como edificio cultual, es de propiedad privada. La intervención arqueológica estuvo motivada por el proyecto de construcción de una vivienda unifamiliar promovida por D. Fidel Delgado Sadornil, quien financió los trabajos arqueológicos y a quien desde aquí queremos agradecer el interés mostrado. 
la existencia de un taller en Frandovínez, ha permitido indagar en aspectos relacionados con la contratación de la obra, el montante económico, y los diferentes oficios que participaron en la empresa.
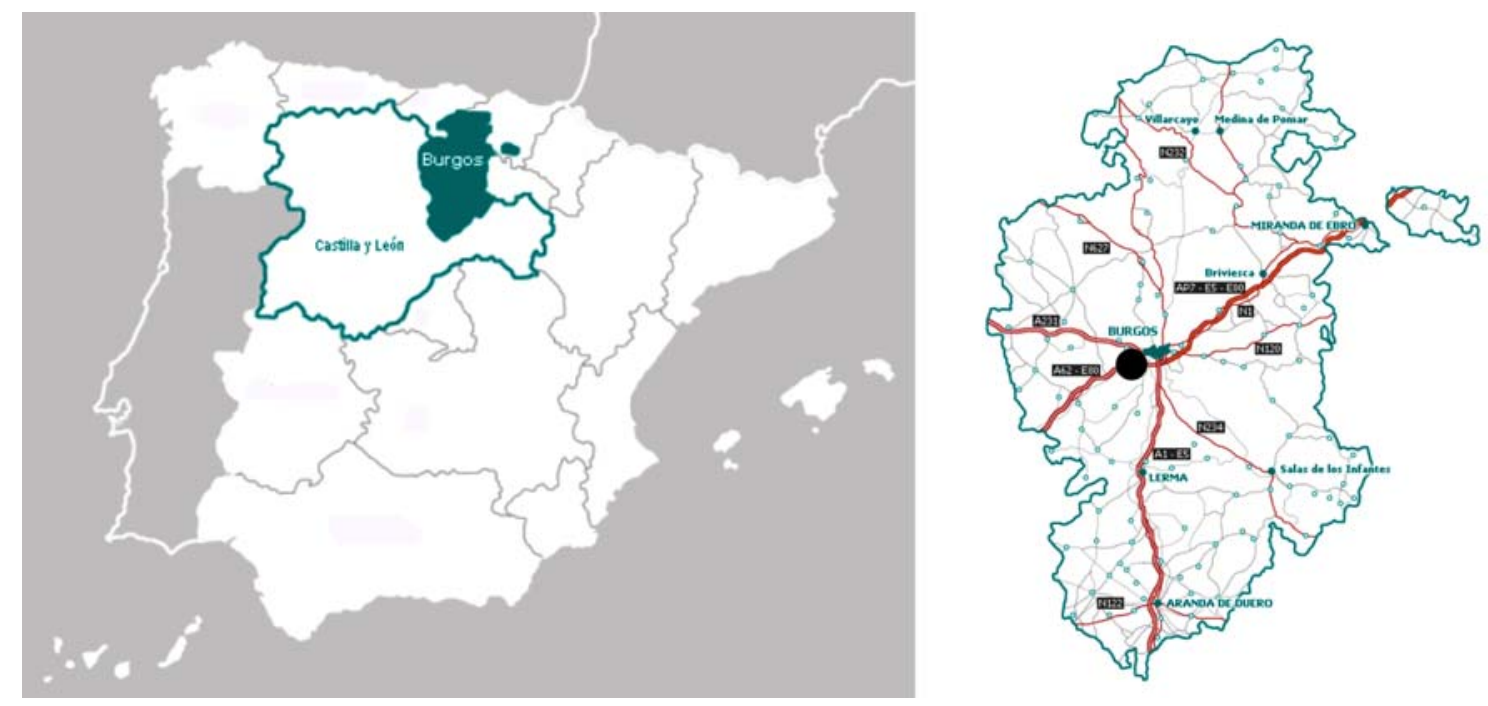

Fig. 1: Localización de la ermita de la Vera Cruz (Frandovínez, Burgos)

Por otro lado, la excavación arqueológica ha deparado otros interesantes resultados, que quedan fuera del alcance de este artículo, relacionados con el devenir histórico del edificio cultual: su uso funerario puntual hasta el año 1812, y el descubrimiento de un silo posiblemente construido durante la ocupación de la localidad por las tropas napoleónicas en el año 1813; siendo especialmente relevante la documentación de varios silos prehistóricos excavados en el sustrato geológico y finalmente amortizados como basureros, que forman parte de un "campo de hoyos" asociado a un lugar habitacional al aire libre Calcolítico (3.300-2.300 cal BC).

\section{LA ERMITA DE LA VERA CRUZ}

La ermita de la Vera Cruz es un pequeño edificio de planta rectangular de 19 metros de lado y 6 de anchura localizado en el límite occidental del núcleo urbano. En el siglo XIX perdió su función como edificio cultual para pasar a ser utilizado como edificio auxiliar agropecuario. Esto implicó pequeñas modificaciones en su estructura como la apertura en el suroeste de una nueva puerta de acceso, para permitir el paso de vehículos, y el cierre de la portada bajo arco de medio punto situada en el sureste y por la que en origen se accedía al edificio. Cuando se iniciaron los trabajos de excavación arqueológica, los únicos restos que quedaban en pie eran poco más de un metro del arranque de sus muros de mampostería caliza y la mencionada puerta primigenia de 
acceso, cegada e integrada en las paredes de una construcción adosada. El arco de medio punto se conserva, pero únicamente es visible desde el interior del edificio anejo, identificándose en la ermita en forma de vano rectangular tapiado (Foto 1).

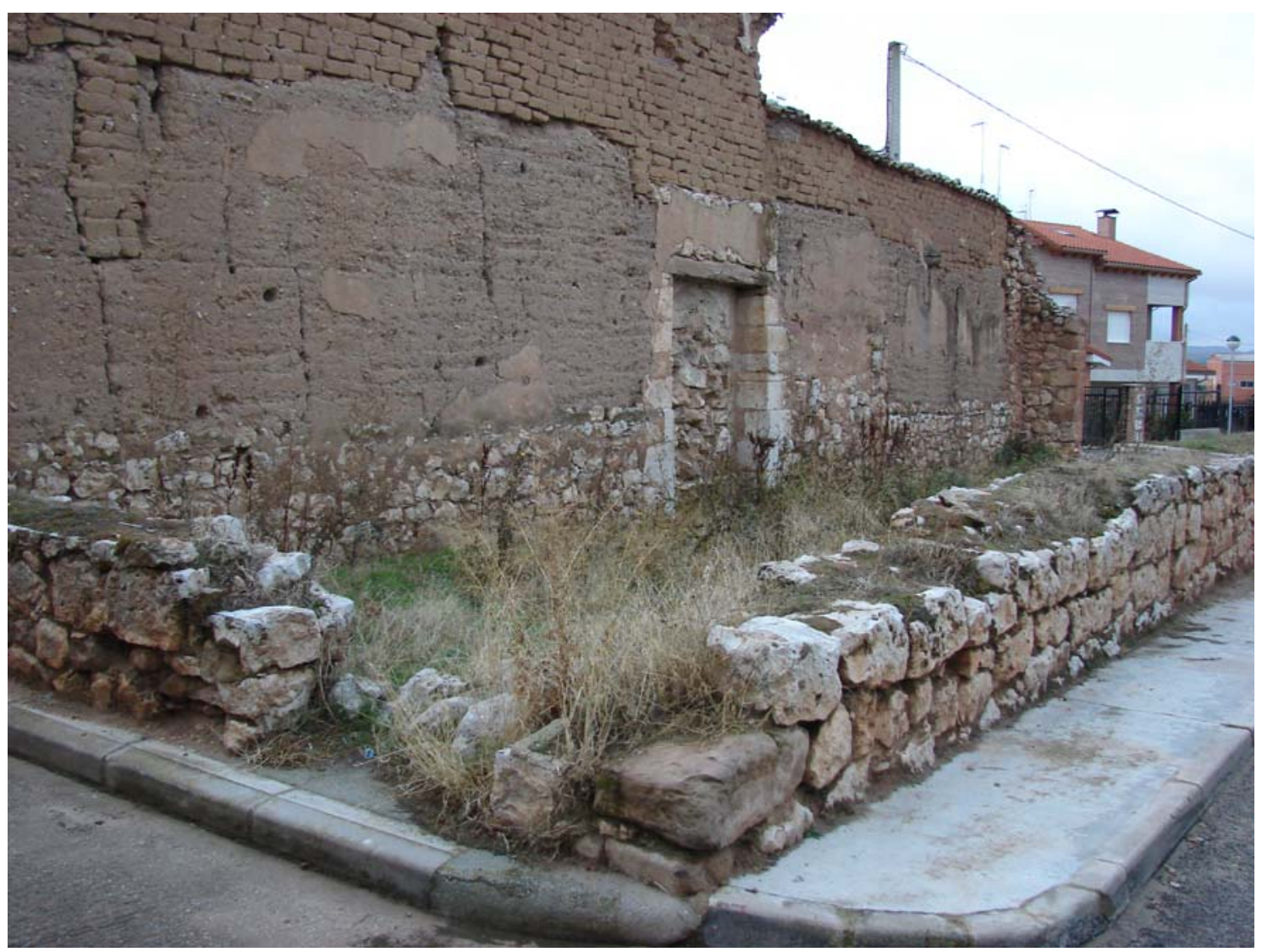

Foto 1: Ermita de la Veracruz antes de la intervención arqueológica: vista desde el norte

Pese a que no existen datos documentales sobre la fecha de construcción, todos los indicios apuntan a que debió realizarse hacia mitad del siglo XVI, aunque, dada su orientación con tendencia esteoeste pero fuerte derivación norte, no parece una fábrica ex novo sino que posiblemente fue reutilizado un antiguo edificio, quizá de uso agropecuario considerando su localización a las afueras de la población. Al mismo tiempo, no sería extraño que se tratase de la donación de un cofrade o de una compra comunal, si bien los libros de la cofradía no proporcionan datos en este sentido.

El origen de las cofradías de la Vera Cruz parece que se remonta al siglo $\mathrm{XIV}^{2}{ }^{2}$ aunque será a partir de 1536 cuando alcancen gran

${ }^{2}$ Navarro Espinach, G. 2006. "Las cofradías de la Vera Cruz y de la Sangre de Cristo en la corona de Aragón (siglos XIV-XVI)". Anuario de Estudios Medievales 36: 583-611. 
difusión; año en el que, a instancia del Cardenal Francisco de Quiñones, el pontífice Paulo III concede indulgencia a la hermandad de Toledo mediante vivae vovis oraculo. ${ }^{3}$ La fundación de la cofradía de Frandovínez tuvo lugar a mediados de ese mismo siglo, ya que sus estatutos datan de 1569. ${ }^{4}$ En su Capítulo XXX se menciona "la capilla del crucifijo donde tenemos ntra. devoción".

Según el Libro de Fábrica de la iglesia parroquial de San Miguel Arcángel, en 1788 se fundieron en la localidad una campana y un esquilón para la iglesia. Con este motivo se anotó el gasto pagado al cantero "que retexó, y allano la Hermita en donde se fundieron las Campanas". Aunque no se hace mención expresa de en cuál de las cuatro ermitas que entonces había en la localidad se realizaron estos trabajos, A. Gonzalo ya había apuntado que debió ser en la Vera Cruz, por estar contigua al casco urbano, en lugar llano, y porque ya con anterioridad, en 1652, fue utilizada para guardar la madera destinada a la fabricación del retablo de la iglesia. ${ }^{6}$

Durante la Edad Moderna y Contemporánea el interior del edificio fue utilizado como lugar funerario ocasional. En concreto, la aparición de algunos restos óseos en posición secundaria documentados entre el sedimento de relleno del foso de moldeo y fundición, demuestra un uso funerario anterior a 1788. De cualquier modo fue una práctica puntual, ya que la excavación arqueológica se ha realizado en la totalidad de la superficie de la ermita y no han sido identificadas sepulturas anteriores a la construcción del taller de campanas. A partir del estudio antropológico se ha determinado que los restos pertenecen a un individuo, un niño de entre 8-9 años de edad de muerte. Teniendo en cuenta esto restos y las dimensiones y localización del foso del taller de campanas, que destruiría la tumba, ésta pudo ser la única sepultura existente. La ermita se utilizó con fines funerarios con posterioridad a la construcción del taller una vez más, en 1812, cuando el 17 de octubre "se enterro en la Hermita de la Vera Cruz un parbulo hixo de Pedro Palacios y de Eusebia Melgosa", 7 cuyos restos, pertenecientes a un niño de edad de muerte estimada en 6-

3 Sánchez Herrero, J. 1999: 27-98. "Las cofradías de Semana Santa de Sevilla durante la modernidad”, en R. Sánchez Mantero (coord.), Las Cofradías de Sevilla en la Modernidad: 60. Sevilla: Universidad de Sevilla.

4 Archivo Diocesano de Burgos (ADB), Libro de la Cofradía de la Veracruz, 1569-1602.

5 ADB, fol. 2 vuelta, Libro de Fábrica de la iglesia parroquial de San Miguel, 1788-1859.

${ }^{6}$ Gonzalo Gozalo, A. 2007. Frandovínez: más de mil años: 242-243. Salamanca: Pueblos de Burgos.

7 ADB, fol. 162 vuelta, Libro de difuntos de la iglesia parroquial de San Miguel, 1755-1830. 
9 meses, fueron recuperados durante la excavación arqueológica en una fosa simple localizada en la zona central del edificio, sobre el nivel de amortización del foso.

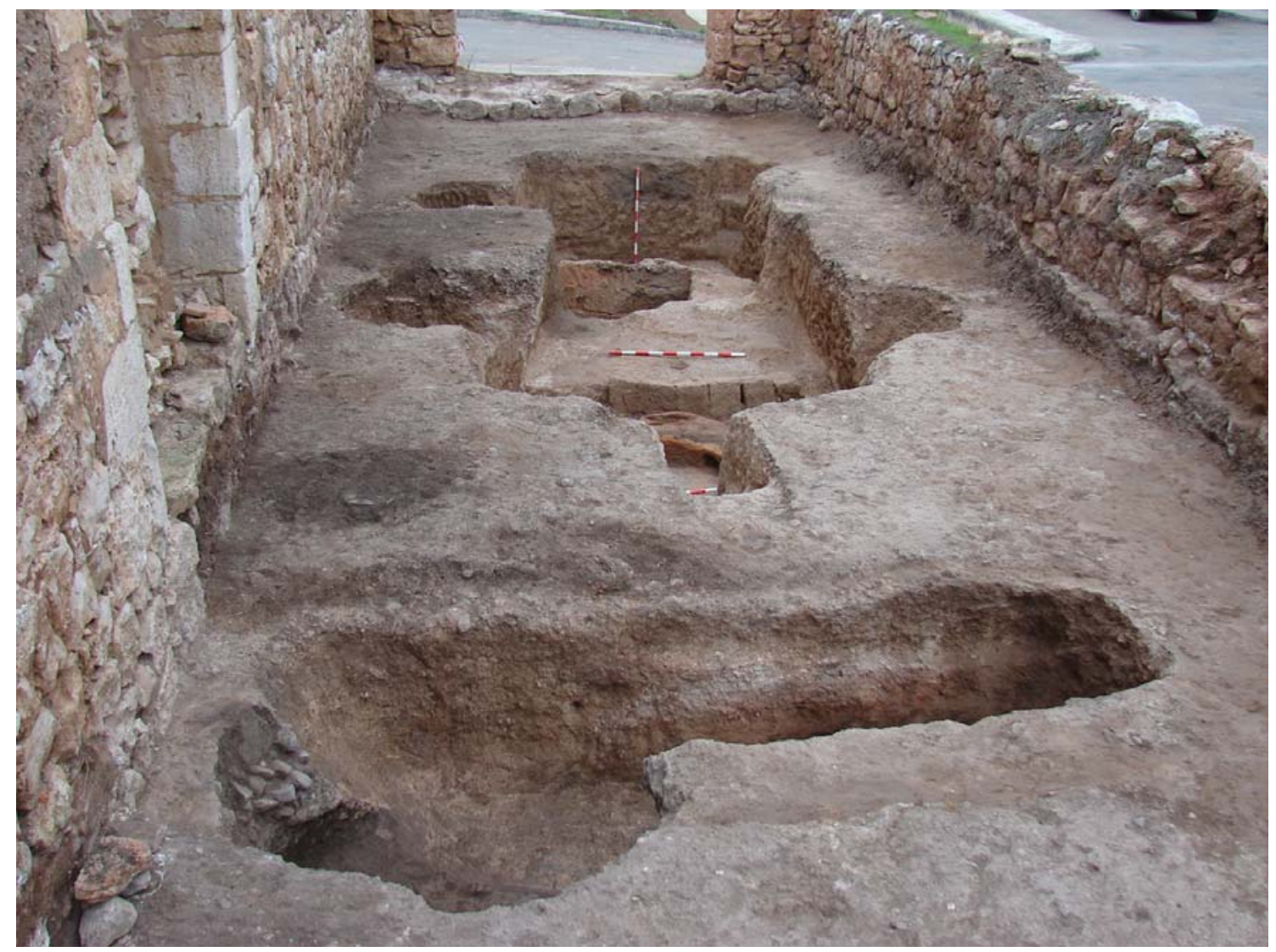

Foto 2: Vista general del taller de fundición, con el horno exterior en primer plano

Muy próximo al paramento septentrional de la ermita también fue descubierto un silo de almacenamiento de forma globular con la boca tapada mediante una laja de piedra caliza, de $130 \mathrm{~cm}$ de diámetro en el fondo y $153 \mathrm{~cm}$ de profundidad. Había sido excavado en el sustrato geológico y en la solera de nivelación integrada por los materiales de la deconstrucción del taller de campanas, por lo que se realizó con posterioridad a este evento. Aunque su contenido no ha deparado materiales arqueológicos que precisen la fecha de construcción, posiblemente se encuentre relacionado con un momento puntual de inestabilidad en el que surgió la necesidad de habilitar espacios para la ocultación de víveres u objetos de valor, quizá durante la ocupación de los franceses de la ciudad de Burgos durante la Guerra de la Independencia, conflicto del que Frandovínez no se mantuvo al margen. 
(BURGOS)

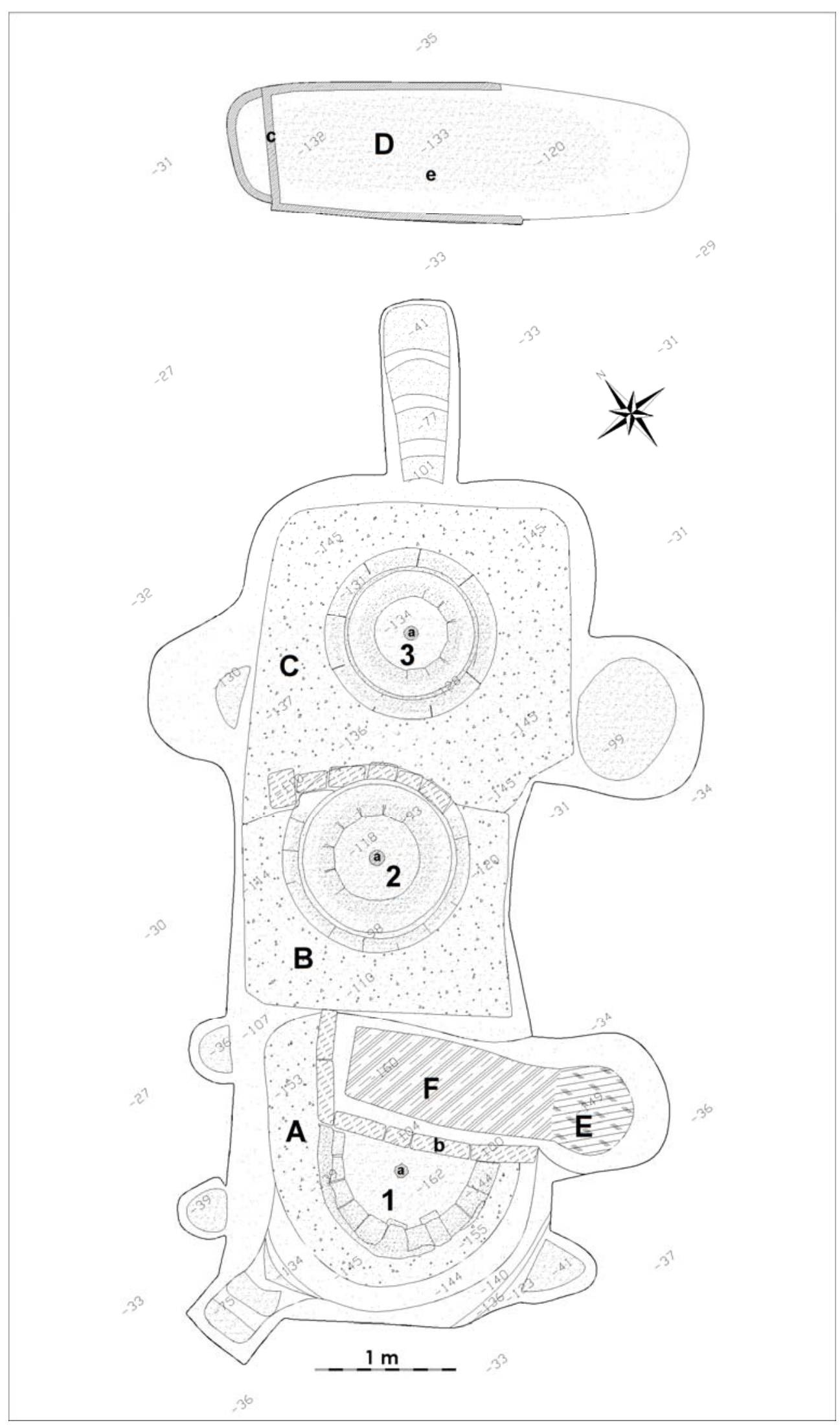

Fig. 2: Planta del taller de fundición 
Especialmente negativas fueron las repercusiones del "alojo" durante cuatro días en junio de 1813 de las tropas francesas ya en retirada, que aprovecharon para asaltar la iglesia y causar graves daños en cultivos y otras propiedades. Los desperfectos fueron detallados por el párroco y el procurador síndico del pueblo en varios documentos. ${ }^{8} \mathrm{El}$ emplazamiento del silo en el interior de un edificio cultual supondría, en principio, una mayor garantía de protección.

El final del uso cultual de la ermita puede situarse en la segunda mitad del siglo XIX. A mediados de esta centuria, Pascual Madoz la cita en su diccionario. La localiza al sur de la población y contigua a la misma, ${ }^{9}$ sin mención alguna sobre su estado de conservación o de culto. Las últimas citas del inmueble en los libros eclesiásticos son de $1824,{ }^{10}$ año en el que concluye el libro de la cofradía, y en la visita pastoral de $1832 .{ }^{11}$

\section{LAS ESTRUCTURAS DE FUNDICIÓN DEL TALLER DE CAMPANAS}

La excavación arqueológica del interior de la ermita ha sacado a la luz los elementos integrantes de un taller de fundición de campanas de finales del siglo XVIII que ocupa prácticamente la totalidad de su superficie (Foto 2). Las principales estructuras documentadas son el foso de moldeo y fundición, que sirvió para alojar los moldes de tres campanas, y dos hornos de reverbero, uno localizado a poca distancia del foso o exterior, y otro construido en el interior. ${ }^{12}$

\section{Foso de moldeo y fundición}

El foso de moldeo y fundición de campanas apareció excavado en el nivel geológico, configurado principalmente por margas blanquecinas compactadas, aunque en cotas superficiales afloran gravas y/o roca caliza semicompactada. La forma de la planta es compleja, aunque fue trazada a partir de un rectángulo base de $6 \mathrm{~m}$ de longitud (con orientación noreste-suroeste) y de anchura variable: $2,30 \mathrm{~m}$ en el este, 2

${ }^{8}$ Gonzalo Gozalo, A. 2011. "Desde la experiencia. El clero de Burgos ante la invasión francesa", en C. Borreguero Beltrán (coord.), La Guerra de la Independencia en el Mosaico Peninsular (1808-1814): 673-693. Burgos: Universidad de Burgos.

${ }^{9}$ Madoz, P. 1850. Diccionario geográfico-estadístico-histórico de España y sus posesiones de ultramar, volumen VIII: 167. Madrid.

${ }_{11}$ ADB, folio 72, Libro de la Cofradía de la Veracruz, 1774-1824.

11 ADB, sin paginar, Libro de Fábrica de la iglesia parroquial de San Miguel, 1788-1859.

${ }^{12}$ Las letras mayúsculas utilizadas en el texto para cada una de las partes integrantes de las estructuras descubiertas, tienen su referente gráfico en las figuras adjuntas. 
m en la zona central, y 2,50 m en el oeste (Foto 3). A partir de este rectángulo fueron excavadas en los laterales una serie de estructuras anejas, como escaleras y fosas de tamaños variados (Fig.2).

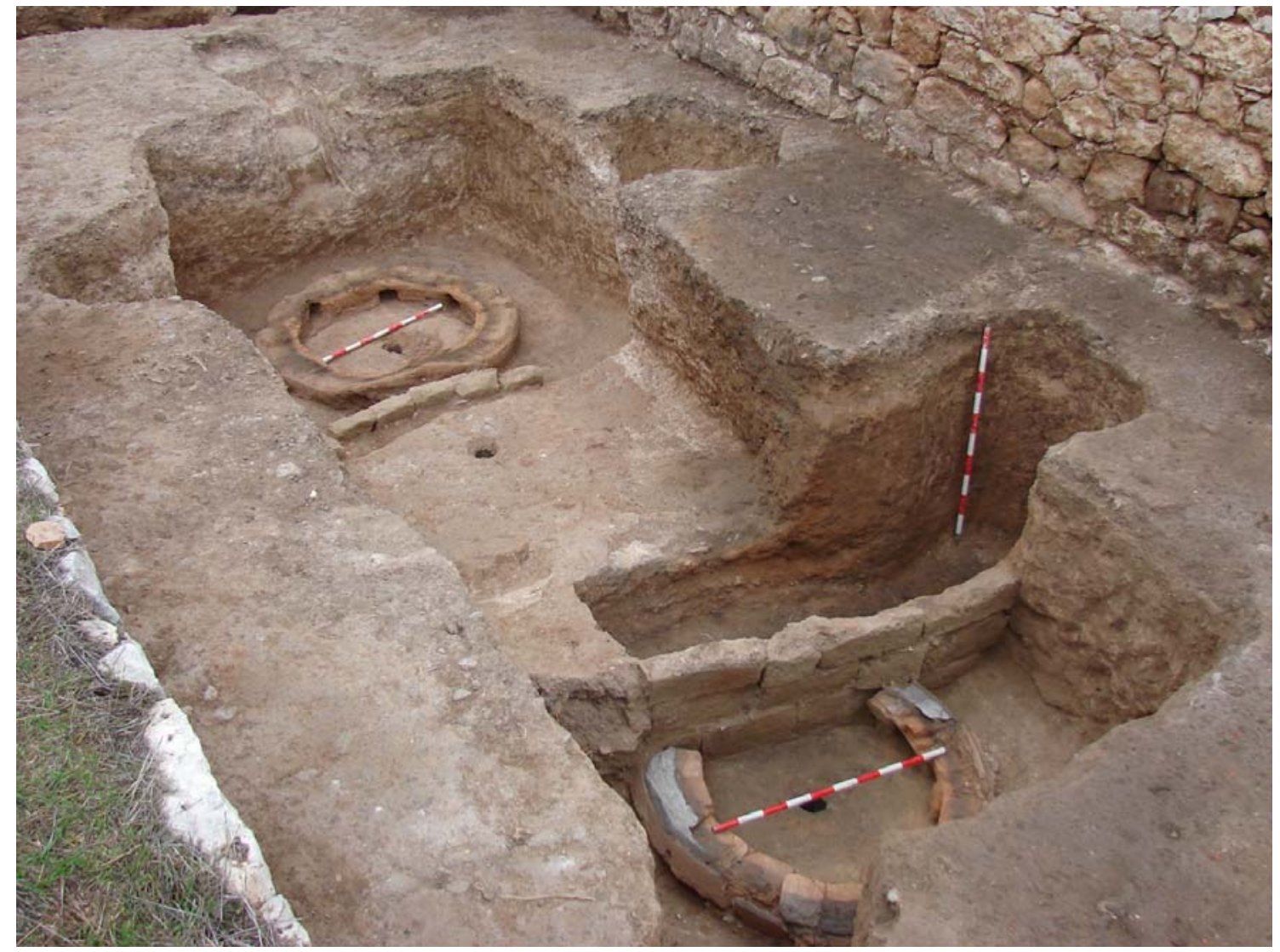

Foto 3: Vista general del taller de fundición, con el molde 1 en primer plano

Todas las esquinas presentan terminación redondeada, tanto a nivel de suelo como en el fondo. A su vez, la estructura está compartimentada en tres espacios o sectores principales dispuestos para la fundición de una campana en cada uno de ellos, siendo el central de menor profundidad que los laterales. El sector más profundo es el más meridional $(A)$, de $132 \mathrm{~cm}$, mientras que el septentrional $(C)$ alcanza los $115 \mathrm{~cm}$, y el central (B) $83 \mathrm{~cm}$ (Fig. 3). La profundidad se puede considerar dentro de la media. En el taller zamorano del convento de San Francisco Extraportem es de $140 \mathrm{~cm},{ }^{13}$ y de $96 \mathrm{~cm}$ en el caso de la

13 Miguel Hernández, H. y Marcos Villán, M.A. 1997. "Arqueología del horno de fundición de campanas del convento de San Francisco Extraportem de Zamora", en E. Gómez Pellón y J. Guerrero Carot (coords.), Las campanas: cultura de un sonido milenario: 450. Santander: Actas del I Congreso Nacional sobre Campanas. Fundación Marcelino Botín. 
ermita de San Francisco de Tomelloso. ${ }^{14}$ Los tres espacios presentan una solera de arcilla muy fina y compactada de color rojizo, de entre 5 y $12 \mathrm{~cm}$ de grosor. La totalidad de la estructura apareció colmatada con una mezcla de materiales constructivos integrados por la arena utilizada para tapar los moldes durante el proceso de colada, fragmentos de tejas, ladrillos planos de terracota y adobes rubefactados procedentes de los moldes de las campanas y de la estructura de los hornos.

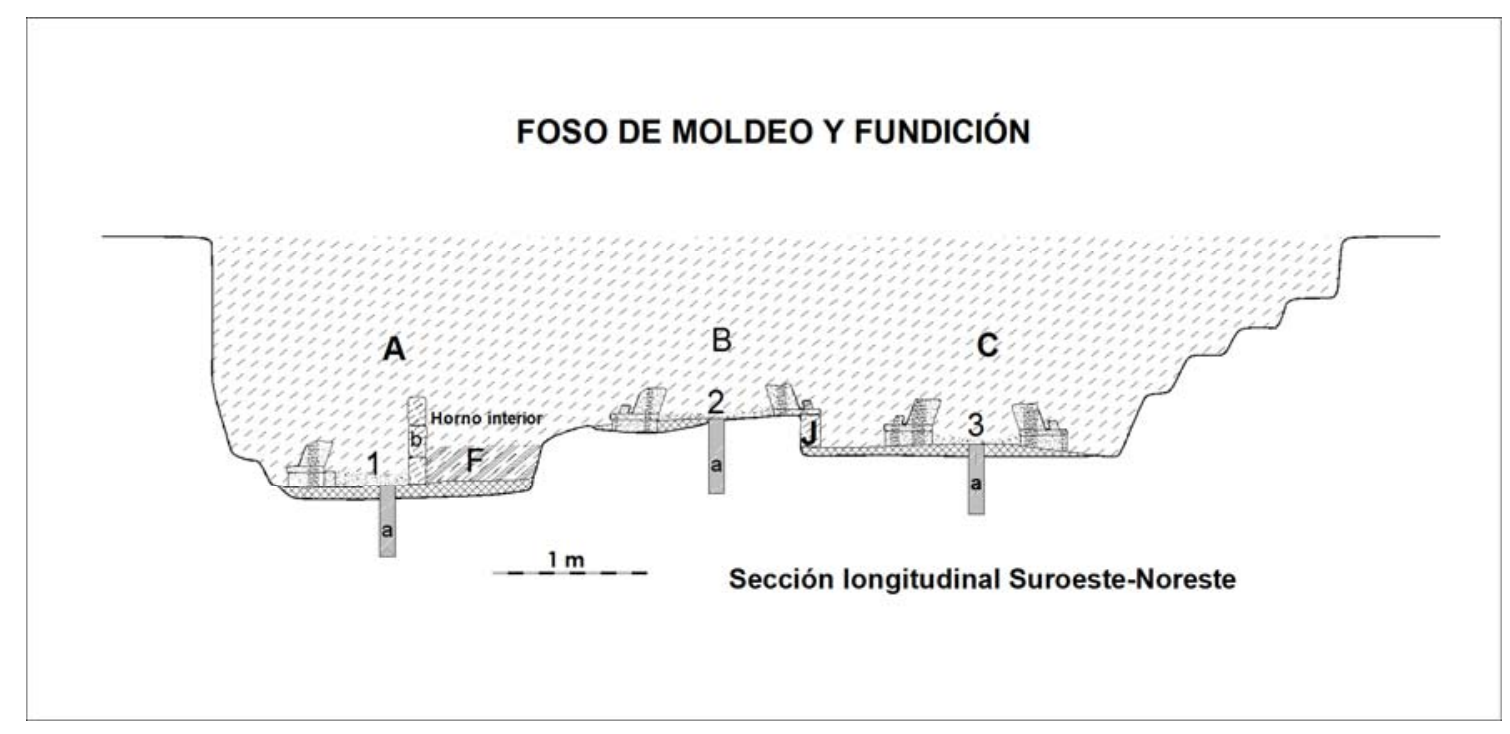

Fig. 3: Sección longitudinal del foso de moldeo y fundición

El sector meridional $(A)$ queda inscrito en un cuadrado de unos 2,30 $\mathrm{m}$ de lado, al que se accede a través de una escalera, localizada en la esquina oeste, igualmente excavada en el sustrato geológico. Aunque el sector presenta a nivel de superficie planta cuadrangular, en la mitad sur del fondo es semicircular, forma que adquiere mediante el tallado de pequeños escalones decrecientes. El centro lo ocupan los restos del molde de la campana $n^{\circ} 1$. Además, fue excavada una fosa de planta circular adosada en el flanco oriental y otras tres pequeñas cavidades de escasa profundidad excavadas en este mismo flanco y en el occidental. La fosa $(E)$, de $97 \mathrm{~cm}$ de diámetro y $113 \mathrm{~cm}$ de profundidad, posiblemente fue excavada originariamente para albergar uno de los moldes de las asas de las campanas, aunque terminó formando parte del hogar del horno interior $(F)$ construido con posterioridad a la fabricación de la campana $n^{\circ} 1$. Con respecto a las tres pequeñas cavidades, su funcionalidad parece estar asociada al apeo de algún tipo de estructura auxiliar al proceso de fundición, relacionada con la sujeción de las

${ }^{14}$ Hervás Herrera, M.A. 2010. "El foso de fundición de campanas de la ermita de San Francisco -siglo XVIII- (Tomelloso, Ciudad Real). Boletín Arqueológico Medieval 14: 110. 
terrajas o con el sistema de poleas y andamiaje necesario para sacar las campanas del foso de fundición una vez terminadas.

El sector central $(B)$ presenta la peculiaridad de contar con menor profundidad que los otros dos, y está individualizado de ambos gracias a un escalón. Presenta planta rectangular de $2 \mathrm{~m}$ de longitud y $1,5 \mathrm{~m}$ de anchura, y en su interior han sido documentados los restos del molde de la campana $\mathrm{n}^{\circ} 2$.

Por su parte, el sector septentrional $(C)$, donde fue fundida la campana $\mathrm{n}^{\circ} 3$, es de planta rectangular, de $2,5 \mathrm{~m}$ de longitud y 2,32 $\mathrm{m}$ de anchura. Como sucede en el sector $A$, cuenta con varias estructuras negativas adosadas a sus flancos: una escalera, localizada en el centro del lateral septentrional, y dos fosas similares a la anterior, una en el flanco oriental y otra en el occidental (Fig. 4).

\section{FOSO DE MOLDEO Y FUNDICIÓN}

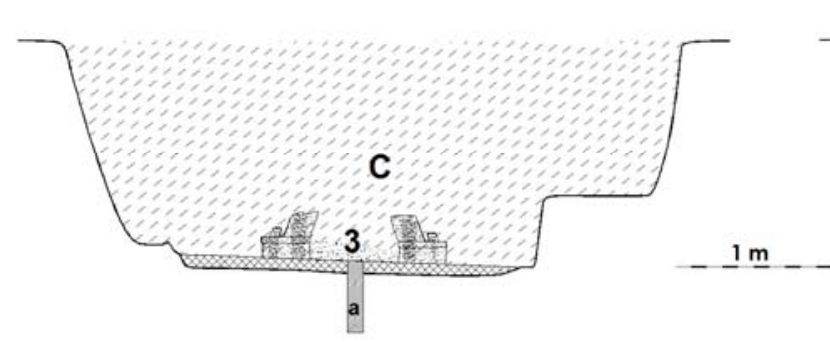

Sección sector $\mathrm{C}$ y molde de la campana $\mathrm{n}^{\circ} 3$

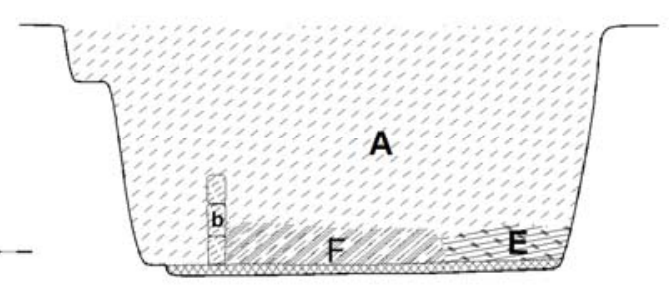

Sección del sector $\mathbf{A}$ en el horno interior

Fig. 4: Secciones trasversales del foso de moldeo y fundición

\section{Horno de reverbero exterior}

El horno $(D)$ fue construido junto al flanco nororiental de foso de fundición, a 1,85 $\mathrm{m}$ de distancia y próximo a la escalera que da acceso al sector $\mathrm{C}$. De este modo, quedaba libre una zona de paso entre ambos elementos directamente enfrentada a la entrada del edificio. Sus principales restos están integrados por una fosa excavada en el sustrato geológico, a igual cota que el foso de fundición, de planta ovalada y sección en bañera con orientación NO-SE. Tiene $340 \mathrm{~cm}$ de longitud, 90 $\mathrm{cm}$ de anchura, y una profundidad de entre $90 \mathrm{~cm}$ al este y $102 \mathrm{~cm}$ al oeste. La pared oriental, donde acusa la menor profundidad, presenta un desarrollo algo más tendido que la meridional (Fig. 5).

Durante la excavación arqueológica pudieron identificarse los restos muy deteriorados del arranque de las paredes de la bóveda y del altillo o escudillo $(c)$ de separación situado entre el crisol y la parrilla, todo 
ello construido con adobes planos. El extremo septentrional, de forma semicircular y que ocupa los primeros $25 \mathrm{~cm}$ de la fosa, se corresponde al espacio destinado a alojar una parrilla metálica. De la misma no se conservan restos, pero sí unos rebajes laterales realizados en las paredes justo en esta zona que pudieron servir para su sustentación.

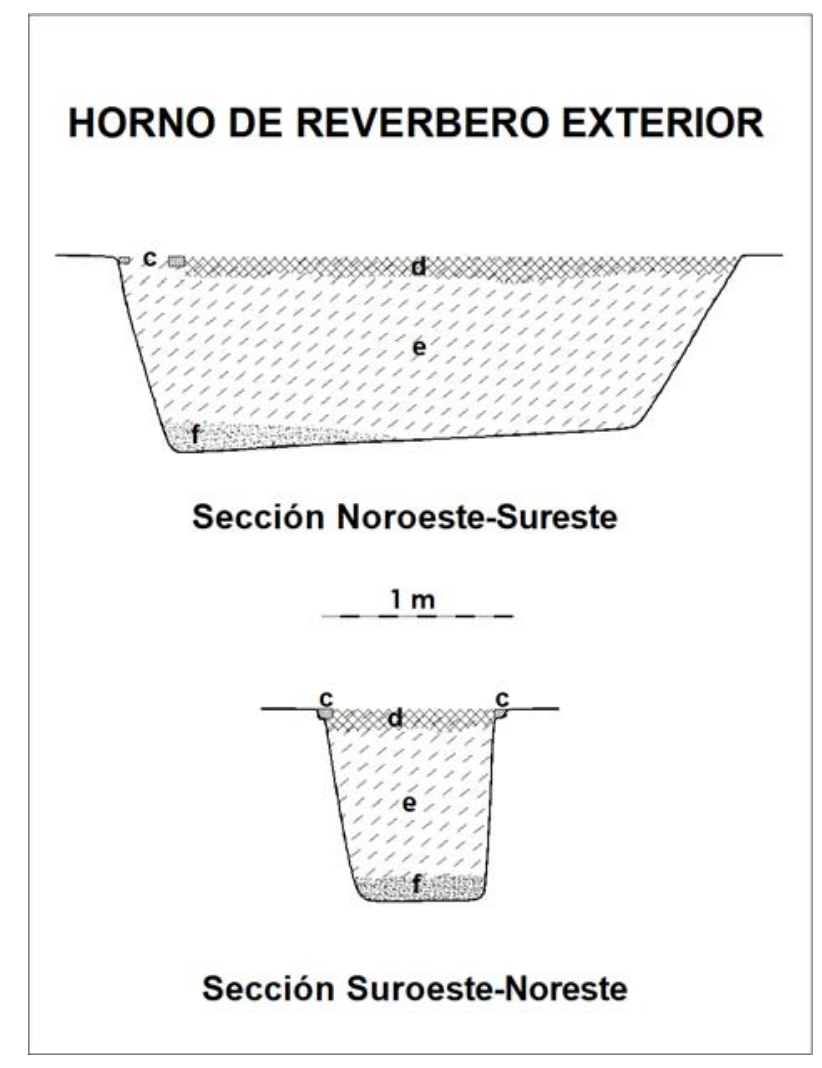

Fig. 5: Secciones del horno de reverbero exterior

La superficie delimitada por el altillo está acondicionada con arcilla tamizada de unos $10 \mathrm{~cm}$ de espesor mezclada con fragmentos de leña carbonizada, que conforma la suela o solera del crisol $(d)$. El resto de la fosa aparece totalmente colmatada con arena, trozos de arcilla decantada, adobe rubefactado, trozos de mortero y fragmentos de tejas (e). El fondo de la estructura, en la zona donde se situaría la parrilla, apareció cubierto por ceniza, fragmentos de madera carbonizada y restos de la colada de bronce (f). ${ }^{15}$

15 Los restos de colada de bronce aparecen de manera abundante en todo el ámbito intervenido, tanto en el interior del foso como en los hornos y en la solera de la ermita. Han sido depositadas varias muestras en el Museo de Burgos, lo que permitirá la realización de análisis metalográficos. 


\section{Horno de reverbero interior}

El horno $(F)$ fue localizado en el interior del foso de fundición aprovechando parte de los elementos que conforman el sector $A$, en concreto la mitad norte de este espacio y la fosa lateral $(E)$ (Figs. 3 y 4 ). Fue construido con posterioridad a la fabricación de la campana $n^{\circ} 1$ mediante la realización de una pared de adobe que cierra la estructura por el oeste y el norte $(b)$, mientras que por el este aprovecha el escalón existente entre los sectores $A$ y $B$. La longitud total asciende a $252 \mathrm{~cm}$, y la anchura media es de $85 \mathrm{~cm}$. El interior, fuertemente rubefactado, se encontraba colmatado por arena, fragmentos de teja, ladrillos planos de terracota y adobes. Sobre este relleno aparecieron restos de la solera o suela del horno, realizada con arcilla tamizada y rubefactada. En la fosa $E$ fue donde se localizó la parrilla. Presentaba en su interior abundante carbón, ceniza de color gris, y pequeñas escorias de colada de bronce.

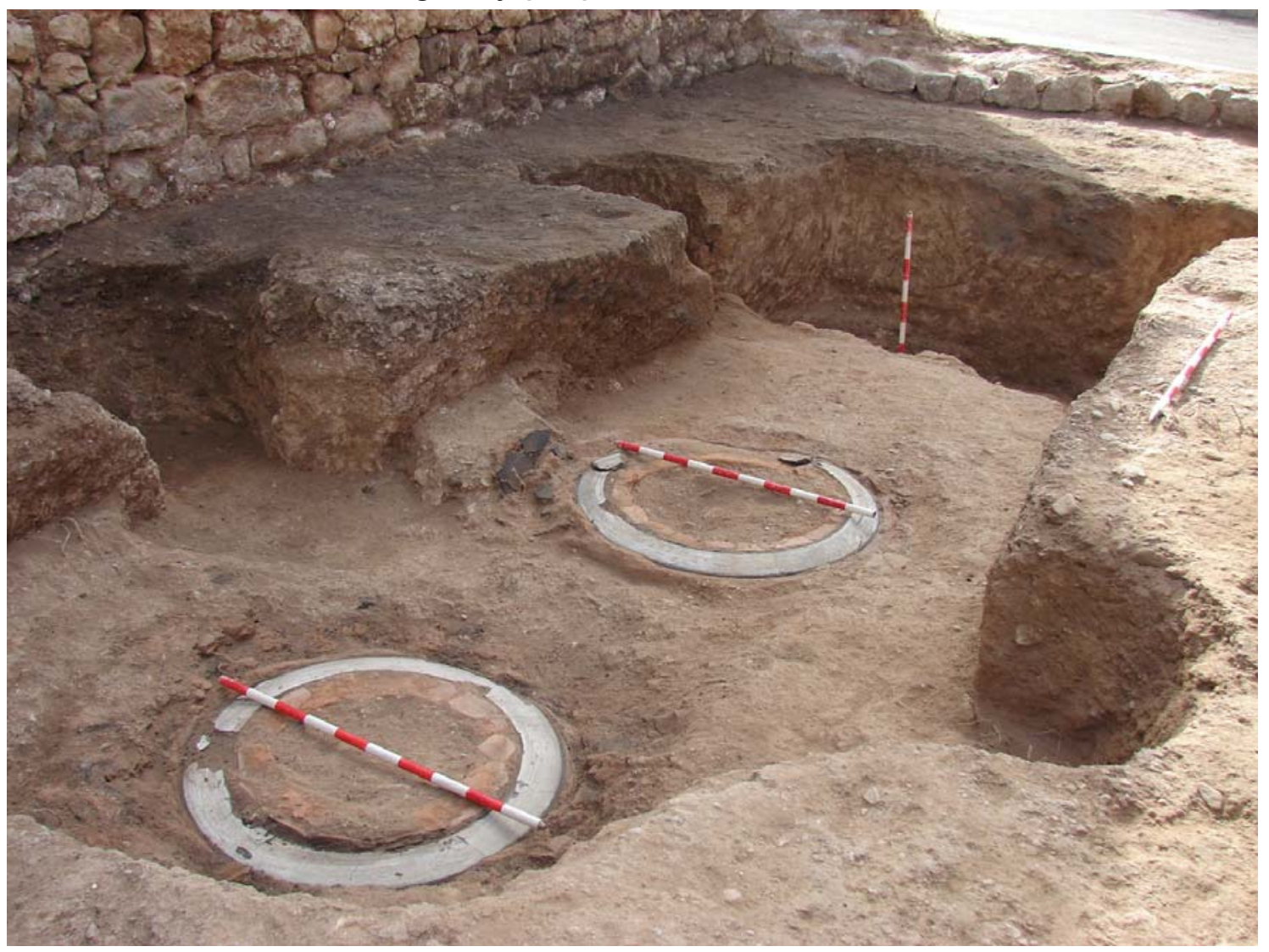

Foto 4: Moldes de las campanas 2 y 3 


\section{Moldes de campanas}

En el interior del foso fueron construidos tres moldes de campanas: el $n^{\circ} 1$ en la zona occidental (sector $A$ ), el $n^{\circ} 2$ en la central (sector $B$ ), y el $n^{\circ} 3$ en la oriental (Sector $C$ ); conservándose evidencias de los diferentes elementos constructivos (Foto 4).

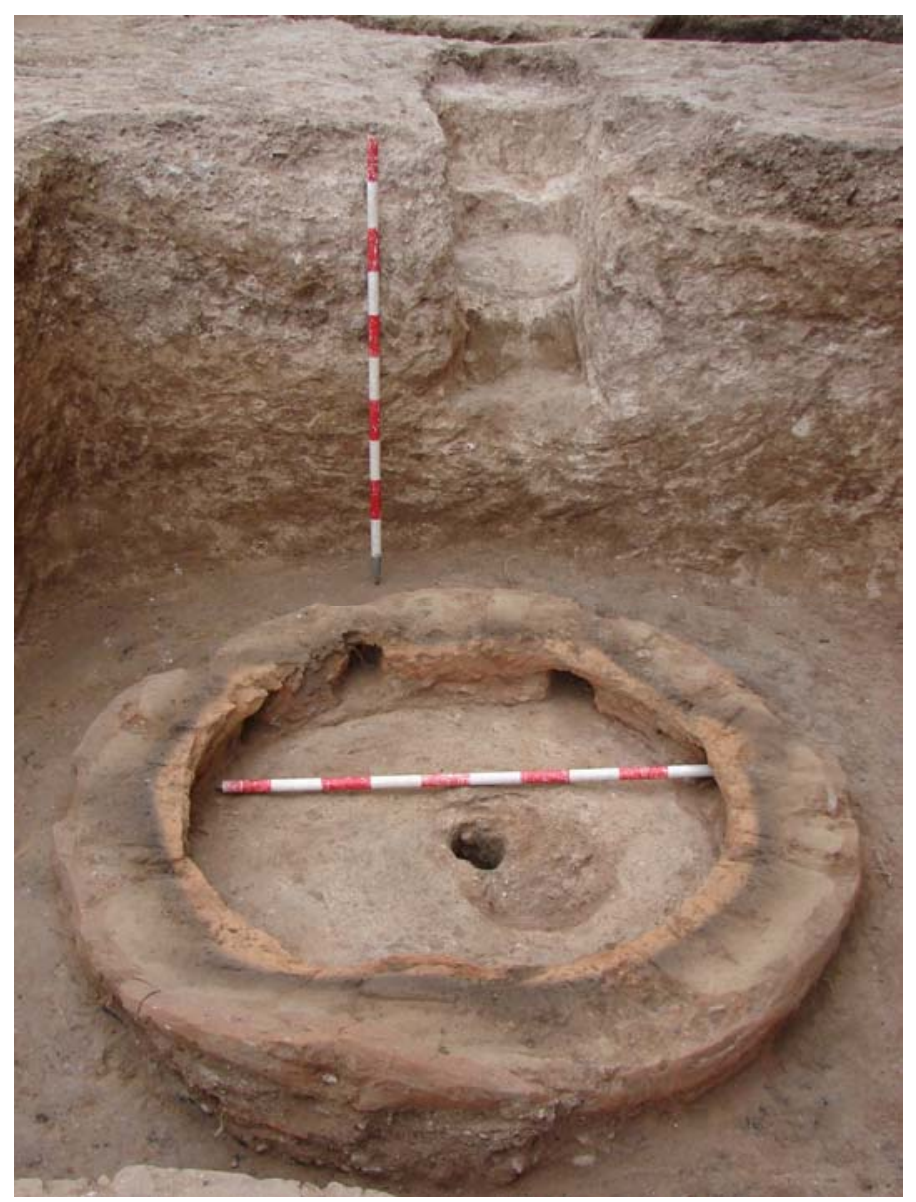

Foto 5: Zócalo del molde 3. Detrás, una de las escaleras para acceder al foso

En el centro de cada molde apareció en perfecto estado la perforación (a) para alojar la barreta o árbol de giro de la terraja, de 10 $\mathrm{cm}$ de diámetro y más de $45 \mathrm{~cm}$ de profundidad. La considerable profundidad resulta llamativa. En el caso del taller zamorano del convento de San Francisco Extraportem es de $25 \mathrm{~cm}$ para una barreta del mismo diámetro, y de $21 \mathrm{~cm}$ en la ermita de San Francisco de Tomelloso. ${ }^{16}$ Los zócalos o muelas que sirven de asiento al molde están realizados con adobes, separados entre sí unos $10 \mathrm{~cm}$ con el fin de

${ }^{16}$ Miguel Hernández, H. y Marcos Villán, M.A. 1997: 455; Hervás Herrera, M.A. 2010: 110. 
poder introducir leña entre ellos y hacer fuego para el secado de las diferentes capas de los moldes: la interior o macho, la falsa campana o camisa y la exterior o capa. Sobre los adobes se dispusieron ladrillos planos de terracota de $3,5 \mathrm{~cm}$ y forma trapezoidal, que facilitaban la configuración de la estructura en circunferencia (Foto 5).

La mayor parte de los restos pertenece a los machos y, en menor medida, a las capas, conservándose fragmentos de los respectivos labios y dientes. Los moldes interiores o machos fueron construidos a base de adobes recubiertos de sucesivas capas de arcilla mezclada con estopa. Con arcilla y estopa también fueron realizados los moldes exteriores o capas. Tanto machos como capas fueron impregnados de ceniza líquida aplicada a brocha para evitar que se adhirieran a sus superficies las falsas campanas o camisas. De estas últimas han sido recuperados algunos fragmentos, identificados por contar con restos en positivo de las inscripciones y ornamentos que tuvieron las campanas.

\section{PROCESO DE FABRICACIÓN DE LAS CAMPANAS}

La intervención arqueológica ha deparado interesantes resultados que permiten avanzar en el conocimiento sobre las técnicas utilizadas en la fundición de campanas en la Edad Moderna. ${ }^{17}$ En Castilla y León han sido varios los obradores de este tipo datados en este periodo y documentados mediante técnicas de excavación arqueológica, pero destacan particularmente el leonés del monasterio de Carracedo ${ }^{18}$ y los situados en la ciudad de Zamora: en el convento de San Francisco Extraportem, ${ }^{19}$ en la iglesia de Santo Tomé $^{20}$ y en la plaza Arias

${ }^{17}$ Queda fuera del ámbito de este trabajo el procedimiento utilizado en la Edad Media para la fundición de campanas, caracterizado por el eje horizontal del modelado, algunos de cuyos talleres también han sido documentados a partir de excavaciones arqueológicas. Una de las primeras intervenciones fue la realizada en la iglesia de Sant Andreu, en Orrius, Girona (Padilla, J.I. y Vives i Balmaña, E. 1983. "Les excavacions a l'eclésia de Sant Andreu (Orrius)", Excavacions Arqueològiques a Catalunya 2: 51-55. Barcelona, Departamento de Cultura de la Generalitat de Catalunya).

${ }^{18}$ Miguel Hernández, H. 1990. "Testimonio arqueológico de una actividad artesanal: la fundición de campanas en el Monasterio de Carracedo (León)”, Bierzo. Milenario del Monasterio de Carracedo.: 145-162. León: Basílica Nuestra Señora de la Virgen de la Encina.

${ }^{19}$ Miguel Hernández, H. y Marcos Villán, M.A. 1997: 439-456.

${ }^{20}$ Viñé Escartín, A.I., Salvador Velasco, M. y Larrén Izquierdo, Hortensia. 1999. "La iglesia románica de Santo Tomé de Zamora y las estructuras excavadas en su entorno", Nvmantia 7: 149-162. 
Gonzalo. ${ }^{21}$ Los restos de Frandovínez son excepcionales, ya que han sido documentadas todas las estructuras integrantes del proceso $\mathrm{y}$, además, existe constatación documental de la fecha de fundición de las campanas en 1788, tal y como figura en el Libro de Fábrica de la iglesia parroquial de San Miguel. ${ }^{22}$ En él se detalla el gasto derivado de tal actividad, que ascendió a 8.640 maravedís:

Campana Por fundir una campana de nuevo se pagaron a el Maestro, que la hizo nobecientos mr vellon ... 900 mrv.

Esquilon Mas se pagaron a otro Maestro quatrocientos, $y$ quarenta $\mathrm{mr}$ vellon de manos, por fundir un Esquilon ... $440 \mathrm{mrv}$.

Metal Mas cinco mil quatrocientas, y sesenta, y quatro $\mathrm{mr}$ pagados a Man(uel) de Linares Vecino en la Ciudad de Burgos de veinte y siete a(ños), y ocho libras de metal, a ocho $\mathrm{mr}$ libra, para fundir otra Campana, $y$ Esquilon ... $5.464 \mathrm{mrv}$.

Mermas Mas se pagaron a el Maestro que la hizo ochocientos, y noventa y siete $\mathrm{mr}$, de la onza en libra, que mermo, por haber ajustado otra campana con la condición de pagarle otra onza en libra ...897 mrv.

Madera Mas ciento, y cinco $\mathrm{mr}$ que costo la madera, para enexar otro Esquilon ... $105 \mathrm{mrv}$.

Carretero Mas dosciento sesenta y dos $\mathrm{mr}$ pagados a el Carretero, que echo la madera en otha Campana, $y$ Esquilon ... $272 \mathrm{mrv}$.

Yerro Mas doscientos, $y$ trece $\mathrm{mr}$ que ha costado el hierro necesario para armar otha Campana y Esquilon ... $213 \mathrm{mrv}$.

Errero Mas Doscientos, y ocho $\mathrm{mr}$ pagados al Errero, por trabajar todo el yerro necesario, para poner en perfección otras Campanas ...208 mrv.

Licencia Mas treinta $\mathrm{mr}$ pagados a el Procurador por la Licencia, que se saco de el Tribunal para hacer las Obras arriba espresadas ... $30 \mathrm{mrv}$.

Carros Mas treinta y dos $\mathrm{mr}$ pagados a los carros que traxeros el Metal, y Maromas de la Cathedral de Burgos, ocupandose tambien en debolberlo ...32 mrv.

21 Sánchez-Monje, M. y Viñé Escartín, A.I. 1993. "Excavación arqueológica en el solar de la plaza Arias Gonzalo (Zamora)", Nvmantia 4: 263280. En esta publicación se hace mención a otros hornos aparecidos en la provincia de Valladolid o en la localidad soriana de Andaluz.

22 ADB folio 2, Libro de Fábrica de la iglesia parroquial de San Miguel, 1788-1859. 
SIGLO XVIII DE LA ERMITA DE VERA CRUZ DE FRANDOVÍNEZ

\section{(BURGOS)}

Refresco Mas veinte $\mathrm{mr}$ y seis $\mathrm{mr}$, que se gastaron con los vecinos que aiudaron a subir las Campanas a la torre ...20 .... 06 mrv.

Madera $\quad$ Mas diez mr pagados a Julian Hortega vecino de esta Villa, por un trozo de madera, que dio a la Iglesia ... $10 \mathrm{mrv}$.

Hermita Mas veinte, y cinco $m r$ y diez y ocho mas pagados al Cantero, que Retexo, y allano la Hermita en donde se fundieron las Campanas arriba espresadas ... 25 .... $18 \mathrm{mrv}$.

El obrador documentado en Frandovínez surgió como consecuencia de una necesidad puntual y concreta, ya que fue realizado por campaneros itinerantes "a pie de obra". Aunque no existen datos sobre la identidad y origen de los artesanos, posiblemente procederían del norte peninsular, ya que la mayoría de los maestros eran naturales del País Vasco, Cantabria y Asturias. A finales del siglo XVII comienza el dominio de los talleres cántabros, procedentes principalmente de la región de Trasmiera, frente a la decadencia de los vizcaínos; ${ }^{23}$ aunque también existen campaneros asentados en la Meseta, como Gregorio Alonso de Aranda de Duero que trabaja en fechas próximas a la registrada en Frandovínez. ${ }^{24}$

La mayoría de los talleres documentados mediante excavaciones arqueológicas han sido localizados "a pie de torre", ya que estas intervenciones suelen estar motivadas por trabajos de restauración en iglesias y monasterios. Sin embargo, desde el punto de vista documental son más numerosos los talleres situados a las afueras de los núcleos urbanos, posiblemente para evitar incendios, eligiendo para tal actividad normalmente patios, corrales o huertos; ${ }^{25}$ de hecho, es frecuente que aparezcan en la documentación bajo la denominación de "corrales de campanas". ${ }^{26}$ En el caso de Frandovínez el lugar elegido fue la ermita de la Vera Cruz, emplazamiento similar al seleccionado en la localidad

${ }^{23}$ Barrio Loza, J.1997. "La campanería de Bizkaia (siglos XVI-XIX). La competencia entre fundidores 'vizcainos' y montañeses”, en E. Gómez Pellón y J. Guerrero Carot (coords.), Las campanas: cultura de un sonido milenario: 122. Santander: Actas del I Congreso Nacional sobre Campanas. Fundación Marcelino Botín.

24 Alonso Ponga, J.L. y Sánchez del Barrio, A. 1997. La Campana. Patrimonio sonoro y lenguaje tradicional. La Colección Quintana en Urueña: 28, 30, 33. Valladolid: Fundación Joaquín Díaz.

25 Ibídem: 29-30.

26 Marcos Villán, M.A. y Miguel Hernández, F. 1998. Maestros campaneros, campanas y su fabricación en Valladolid y su provincia (Siglos XVI a XVIII): 65. Valladolid: Diputación Provincial de Valladolid. 
manchega de Tomelloso en fechas ligeramente anteriores, ${ }^{27}$ situada en el límite occidental del núcleo urbano y sustentada por la cofradía del mismo nombre.

El proceso de fundición comenzaba normalmente con el retejo del edificio elegido como obrador para evitar la entrada del agua de lluvia. ${ }^{28}$ En el caso que nos ocupa, en el Libro de Fábrica aparecen anotados 43 maravedís que se pagaron a un cantero por retejar y allanar la ermita aunque, teniendo en cuenta que se trata del último gasto apuntado relacionado con el proceso, parece que se trata de las labores de restauración del edificio una vez fabricadas las campanas. El retejo fue necesario para tapar las chimeneas de los hornos, y para el allanado fueron utilizados los restos de los materiales constructivos del obrador.

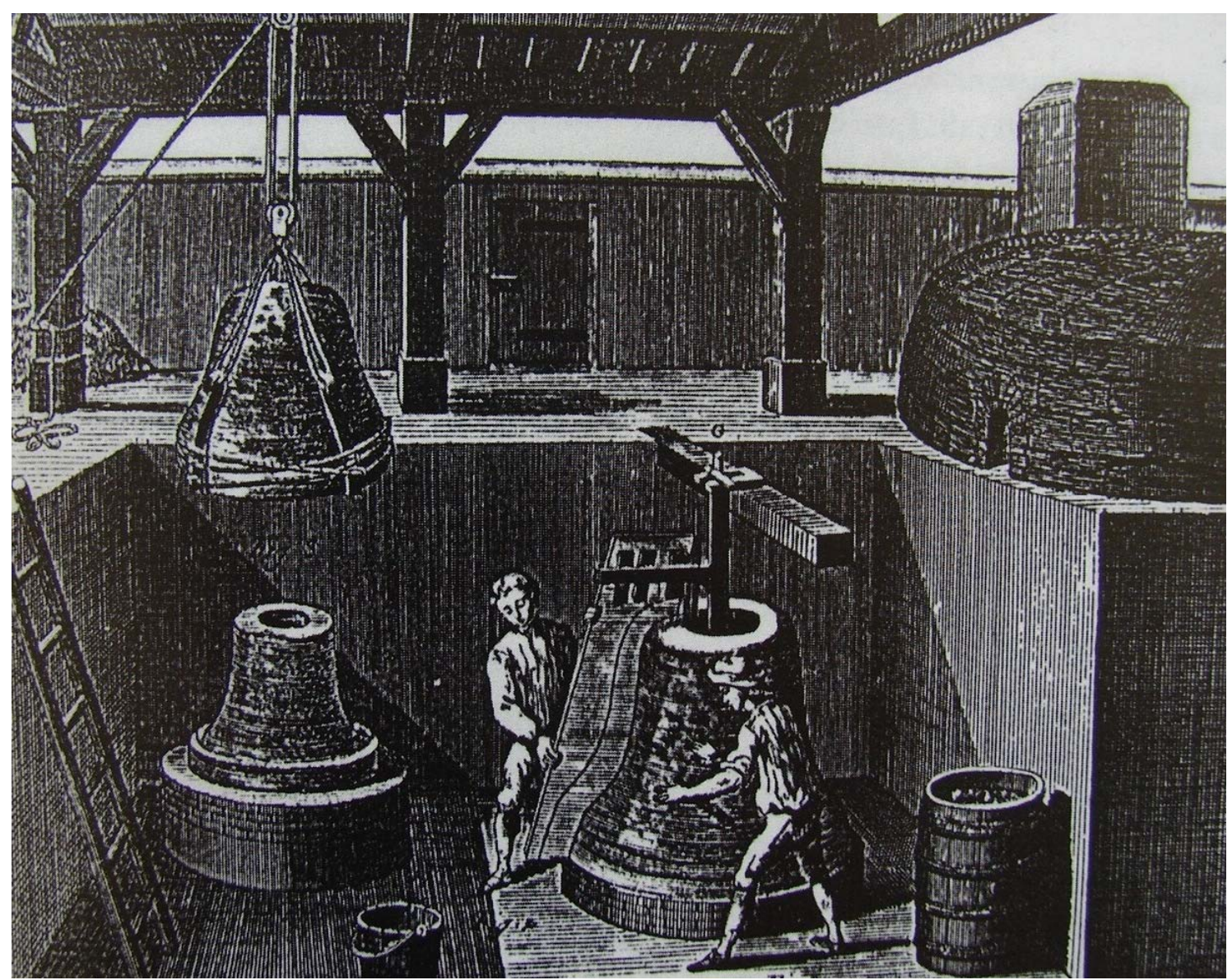

Fig. 6: Taller de fundición de campanas del siglo XVIII. Ilustración de la Enciclopedia de Diderot y D'Alambert

En el Libro de Fábrica consta la fundición de una campana y un esquilón, y que los trabajos los realizaron dos maestros diferentes. La

${ }^{27}$ Hervás Herrera, M.A. 2010:93-127.

${ }^{28}$ Miguel Hernández, H. 1990: 153 
(BURGOS)

excavación arqueológica ha permitido constatar la sucesión de dos eventos de fundición y la existencia de dos hornos de reverbero, pero no han sido dos los moldes de campanas documentados sino tres. Posiblemente las instalaciones del obrador fueron aprovechadas para fundir una campana para la iglesia de otra localidad, algo no infrecuente, ${ }^{29}$ por lo que al no ser un gasto que tuviera que asumir la parroquia no se hizo constar en el Libro de Fábrica.

La denominación de campana y esquilón en principio parece hacer alusión a las dimensiones de las piezas; sin embargo, la diferencia de tamaño de las campanas fundidas en base a las medidas de los moldes no parece muy acusada, con diámetros estimados en $135 \mathrm{~cm}$ (campana $\mathrm{n}^{\circ}$ 1), $110 \mathrm{~cm}$ (campana $\mathrm{n}^{\circ} 2$ ) y $95 \mathrm{~cm}$ (campana $\mathrm{n}^{\circ} 3$ ). Por otro lado, aunque el término "esquilón" se aplica por lo general a las campanas de menor tamaño, la documentación existente sobre el gramaje de este tipo de piezas informa de una amplia gama de pesos y, por lo tanto, de tamaños. Por ejemplo, el esquilón que se fundió en 1629 para la iglesia de Santa María de Medina del Campo pesaba un quintal escaso (46 kilos), mientras que el que se fundió en Cantalejo de la Piedra (Salamanca) en el siglo XVI pesaba 9 quintales (414 kilos). Los pesos de otros esquilones fundidos en Valladolid y Salamanca oscilan entre los 160 y los 300 kilos. $^{30}$ Los estudios realizados en campanas góticas de Castilla y León ${ }^{31}$ apuntan hacia una clara diferenciación entre campanas y esquilones: las primeras serían de tamaño grande, también denominadas romanas, de hombros y paredes rectas bruscamente abombadas en el pié, emiten sonidos graves y su peso se sitúa entre 10 y 34 quintales (460-1.472 kg). Por su parte, los esquilones tienen perfil más alargado, emiten sonidos agudos y claros, y pesan entre 1 y 9 quintales (46-414 kg).

El proceso de fabricación constatado en Frandovínez es básicamente el mismo descrito en la Enciclopedia Francesa, obra del Abad Pluche, traducida al español por el Padre Terreros bajo el título Espectáculo de la Naturaleza (Madrid 1773, Parte VII, Tomo XIV, p. 100) o en la Enciclopedia de Diderot y D'Alambert publicada entre 1751 y 1772 (Fig. 6), proceso de fabricación que se mantendrá prácticamente sin cambios hasta el siglo $\mathrm{XIX}^{32}$ Los trabajos comienzan con la excavación del foso de moldeo y fundición. El molde puede ser construido en el exterior para luego transportarlo al foso, pero en

${ }^{29}$ Hervás Herrera, M.A. 2010: 104.

30 Marcos Villán, M.A. y Miguel Hernández, F. 1998: 42.

31 Palacios Sanz, J.I. 2010: "Campanas góticas de Castilla y León. Un patrimonio sonoro". Acta Histórica et Archaeologica Medievalia 30: 419-420.

${ }^{32}$ Marcos Villán, M.A. y Miguel Hernández, F. 1998: 16. 
Frandovínez los tres moldes fueron construidos en el interior, en el mismo lugar en el que se procedió a la fundición, ya que han sido documentados los restos del árbol de giro de las terrajas de madera. Estas piezas tienen la silueta del perfil que se le quiere dar a las campanas, y cuentan con un giro de $360^{\circ}$ (Fig. 7).

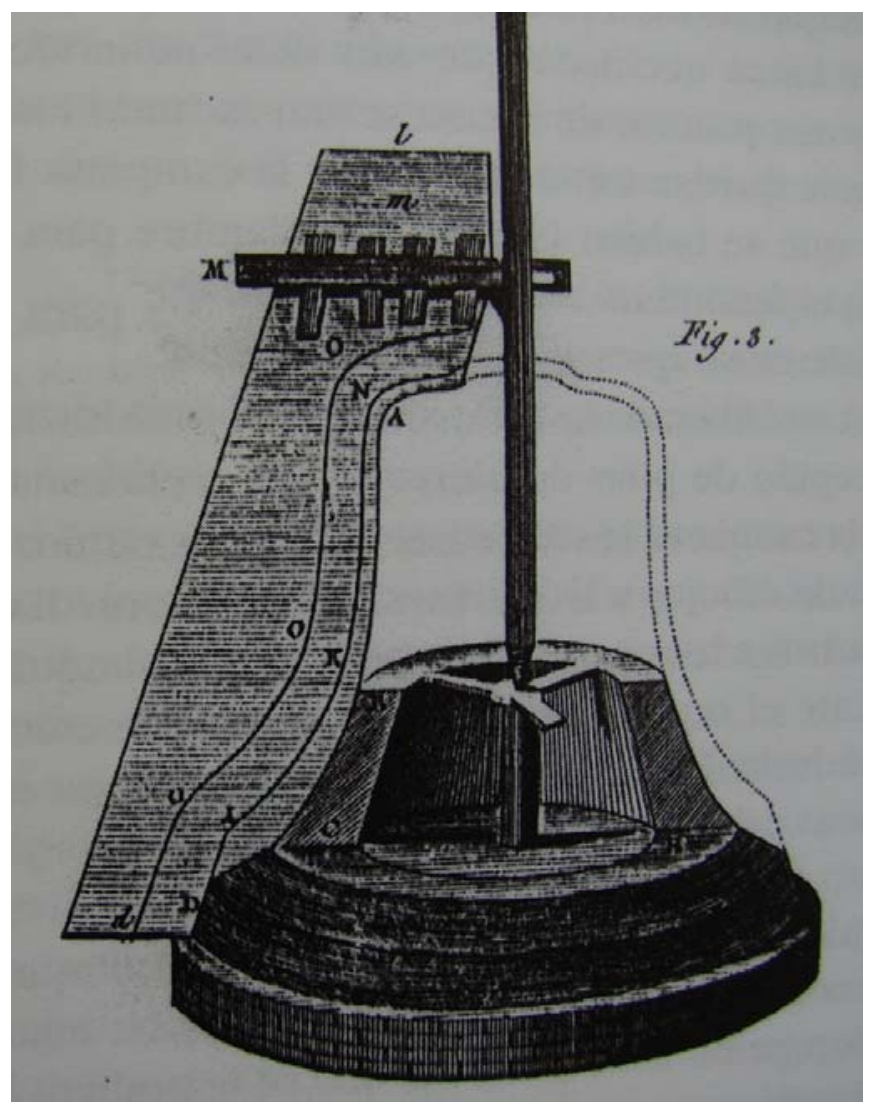

Fig. 7: Terraja y sección de los moldes de una campana. Ilustración de la Enciclopedia de Diderot y D'Alambert

El foso, excavado en el sustrato geológico, presenta planta compleja a partir de un rectángulo base del que surgen una serie de estructuras negativas anejas: dos escaleras, tres fosas que parecen haber servido para la fundición de los moldes de las asas (Foto 6) -una de ellas terminó formando parte del hogar del horno interior-, y tres pequeñas cavidades cuya funcionalidad parece estar asociada al apeo de algún tipo de estructura auxiliar al proceso de fundición. En este sentido, han sido recuperados varios clavos de hierro que debieron servir para la sujeción de andamios, barquines o fuelles, y otros elementos auxiliares relacionados con el proceso.

El interior fue compartimentado en los tres sectores anteriormente descritos, cada uno de ellos destinado a la fundición de una campana, y 
cubiertos con una solera de arcilla muy fina y compactada localizada en el fondo pero sin llegar a las paredes. Se trata de una solución similar a la documentada en el obrador del monasterio de San Francisco de Zamora, $^{33}$ aunque en otros fosos no han sido documentados revestimientos ni preparación especial alguna. ${ }^{34}$ Posiblemente su funcionalidad esté relacionada con mantener limpio el ámbito de trabajo mientras se procede a la realización de los diferentes moldes.

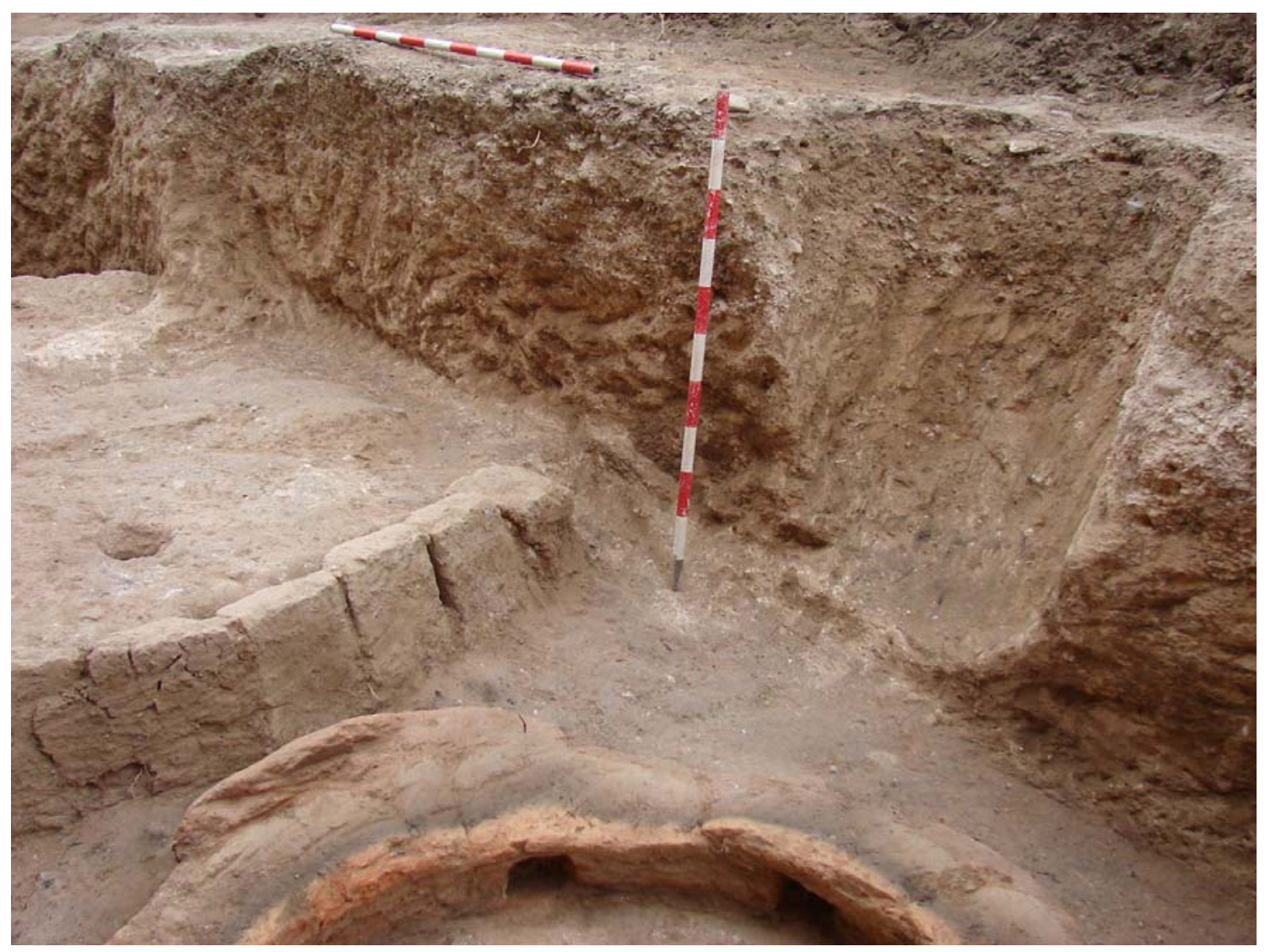

Foto 6: Una de las tres fosas que pudieron servir para la fundición de los moldes de las asas

Una vez acondicionada la solera fueron fabricados los moldes siguiendo las pautas generalmente utilizadas, empezando por la construcción del zócalo o muela que servirá de asiento al molde. En Frandovínez, en los tres casos se encuentra realizado con adobes separados entre sí con el fin de poder introducir leña entre los agujeros y hacer fuego para el secado de los moldes (Foto 7 ). ${ }^{35}$ Sobre esta primera

${ }^{33}$ Miguel Hernández, H. y Marcos Villán, M.A. 1997: 448.

${ }^{34}$ Hervás Herrera, M.A. 2010: 110.

35 En este proceso también era habitual la utilización de ladrillos fragmentados (Miguel Hernández, H. y Marcos Villán, M.A. 1997: 453; Hervás Herrera, M.A. 2010: 105. 
hilera de adobes o peón se colocaron ladrillos planos de terracota, que por su forma trapezoidal permiten configurar una circunferencia. En el eje central de cada zócalo fue hincado la barreta o árbol de giro de la terraja, de cuyo interior han sido recuperados los restos carbonizados de los troncos de madera utilizados como ejes, que parecen corresponder a olmo o encina.

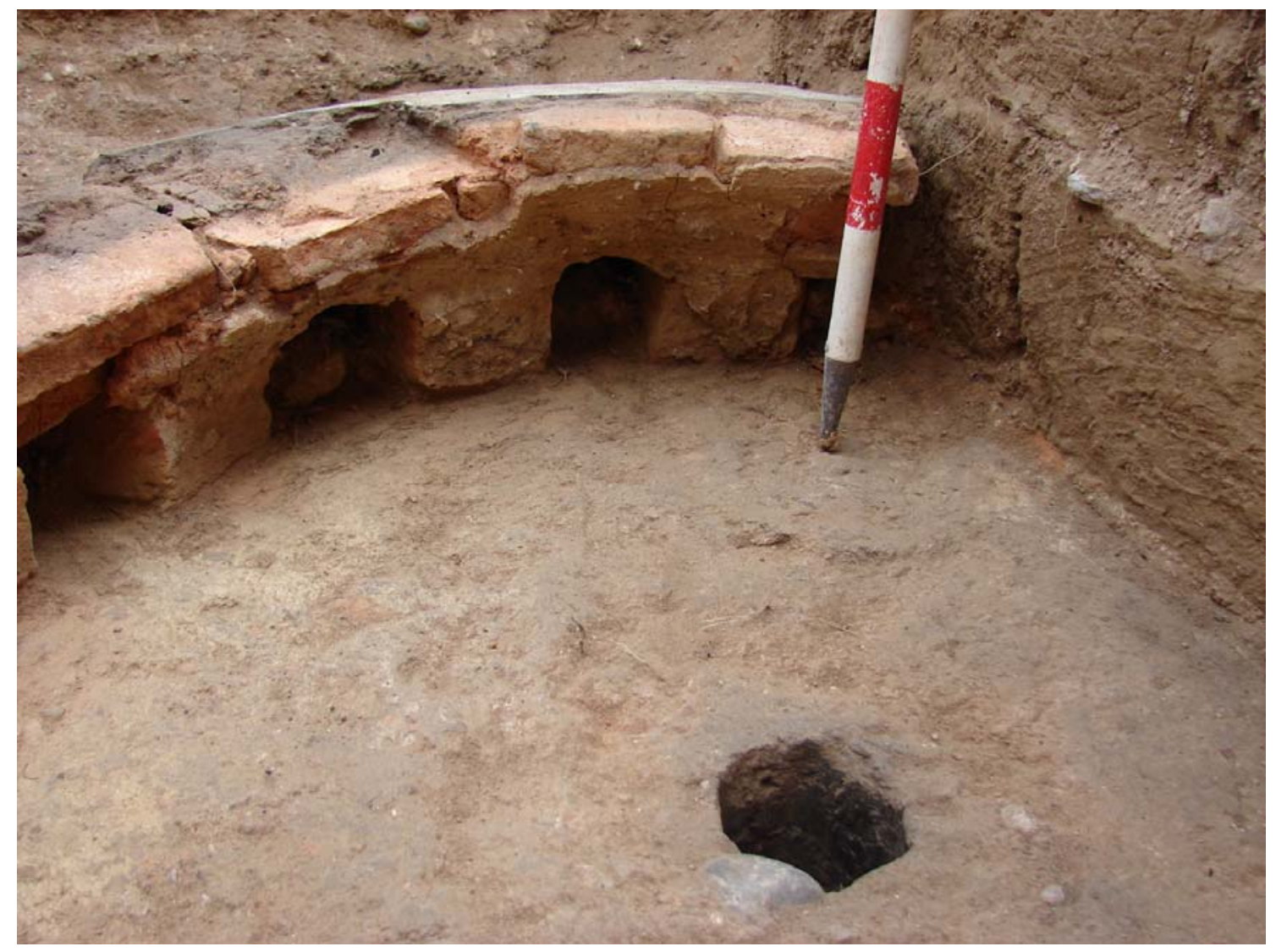

Foto 7: Zócalo y agujero para el árbol de giro de la terraja del molde 1

A partir del zócalo se comienza la construcción del molde interior o macho a base de adobe. Estos adobes han sido recuperados, generalmente fragmentados, tanto en los propios moldes como en el interior del foso de fundición y en la solera del edificio. El macho suele ser reforzado con alambre, como ha sido constatado en la ermita de San Francisco de Tomelloso, ${ }^{36}$ o hilo, aunque en Frandovínez no se han encontrado restos de estos materiales. Con el fin de evitar agrietamientos, se cubre con arcilla fina mezclada con estopa y se aplica una última capa mezclada con estiércol, preferentemente de equino. Durante todo este proceso la terraja va girando con el fin de ajustar perfectamente el molde a las dimensiones deseadas, y se procede a

${ }^{36}$ Hervás Herrera, M.A. 2010: 114. 
encender fuego en el interior de la estructura a través de los agujeros dejados en el zócalo para que se sequen las sucesivas capas de barro.

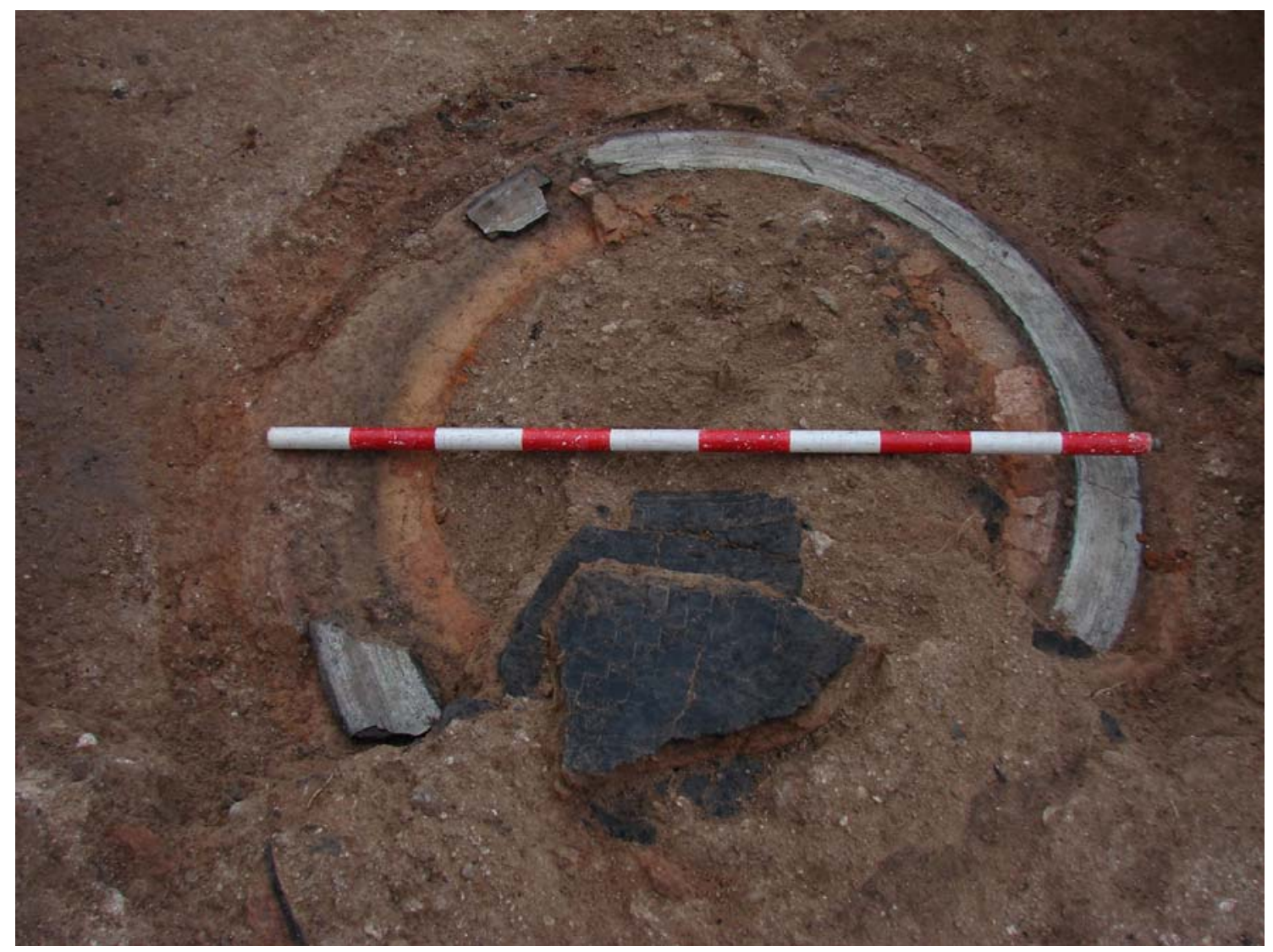

Foto 8: Molde de la campana 2, con restos decorados de la capa

Cuando el macho se encuentra terminado se fabrica la falsa campana o camisa, utilizando una nueva terraja que determinará el perfil exterior de la campana. En este caso puede tener unas muescas para imprimir los clásicos cordones que decoran las campanas -siendo este el motivo más habitual-, ${ }^{37}$ entre los que suelen ir enmarcadas las inscripciones. Para evitar que se adhiera demasiado al macho, éste es impregnado de una capa de ceniza líquida que en el caso que nos ocupa ha sido aplicada a brocha. La camisa se fabrica a base de capas de barro, aunque finalmente se le aplica sebo o clara de huevo y resina para evitar que se adhiera al molde exterior o capa. En este momento pueden colocarse las inscripciones y decoraciones que tendrá la campana, mediante la aplicación de sellos de cera previamente fabricados en moldes de madera. En la Vera Cruz han sido recuperados algunos fragmentos de la capa de la campana $n^{\circ} 2$ decorados con elementos

${ }^{37}$ Palacios Sanz, J.I. 2010: 443. 
ornamentales en negativo (Foto 8): una cruz de calvario apuntada con decoración floral y cabezas de clavo rematadas con estrellas -el diseño a base de formas vegetales se rastrea ya en las campanas medievales-, ${ }^{38}$ y gradas con ajedrezado de lises de cinco pétalos. Precisamente la cruz potenzada sobre pedestal es el motivo ornamental más característico de las campanas castellano-leonesas, y debe ser entendido como elemento protector contra espíritus malignos y calamidades tradicionalmente relacionadas con desastres naturales. ${ }^{39}$ De esta misma campana también se conservan algunos fragmentos y letras de la inscripción en letra capital, -[-]O - CVR[-]- (Foto 9). Por otro lado, del sedimento de relleno del foso proceden dos fragmentos con letras cursivas ilegibles en positivo que parecen formar parte de la camisa de una de las campanas. No ha sido posible descifrar el contenido de las inscripciones que, por lo general y desde el mundo medieval, parten de frases piadosas extraídas de los salmos o tomadas de la 'Leyenda dorada' del obispo genovés Jacobo de la Vorágine. ${ }^{40}$

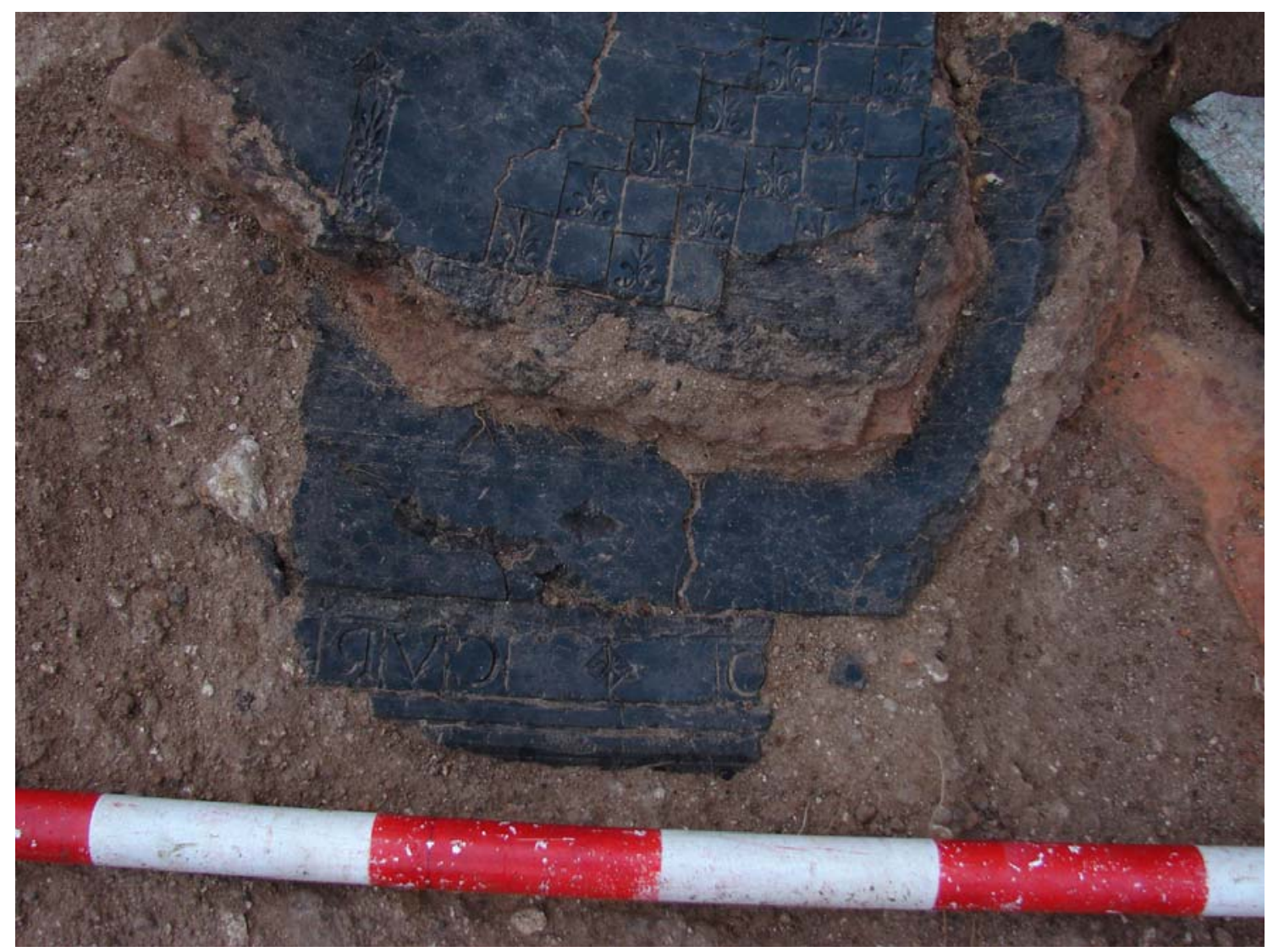

Foto 9: Detalle de la decoración de la capa del molde 2

\footnotetext{
38 Ibídem: 433.

39 Ídem.

40 Ibídem: 425.
} 
La fabricación de la capa comienza con la aplicación a pincel de sucesivas manos de arcilla líquida. La primera de ellas, denominada calderada o lisa, mediante arcilla fina, clara de huevo, sangre y pelo de conejo. Posteriormente se aplican otras capas de arcilla mezclada con estopa o con estiércol, y finalmente una gruesa capa de arena y paja para evitar agrietamientos que puede ir acompañada de alambre, aunque no hemos encontrado evidencias del uso de este material. Por último, se procede a secar el molde mediante la introducción de más leña entre el zócalo. Durante el proceso, denominado recocido, estufado o enjugado, también se derrite la cera de los sellos decorativos.

Tras el secado, la capa es retirada y se rompe la falsa campana, haciendo los retoques oportunos para depurar posibles fallos en la superficie de la primera antes de colocarla sobre el macho. Terminada la operación, el macho es rellenado con arena, se introduce la anilla que servirá para la sujeción del badajo, y se colocan los moldes de las asas. El proceso concluye con la preparación de dos perforaciones o bebederos para la entrada de la colada, y otras dos perforaciones 0 suspirales que permitan la desgasificación.

Los moldes de las asas eran confeccionados generalmente en barro a partir de un núcleo de cera, y en ocasiones cocidos en agujeros excavados a tal efecto. Esta parece haber sido la utilidad de las tres fosas de tendencia circular que fueron excavadas junto a las paredes del foso.

El molde de la campana $n^{\circ} 1$, localizado en el sector occidental, el de mayor profundidad, fue el primero que se construyó. Se trata de la campana de mayores dimensiones, con un diámetro estimado en 135 $\mathrm{cm}$, y fue fundida con la colada preparada en el horno de reverbero exterior al foso. Teniendo en cuenta que las dimensiones de este horno son superiores a las del interior, parece lógico pensar que a su vez se fundió la colada de otra campana. Posiblemente se trata de la campana $\mathrm{n}^{\circ} 2$, localizada en el sector central y ubicada a menor profundidad, ya que en el Libro de Fábrica aparece anotado un gasto en calidad de "Mermas" en el que se afirma que se "ajusto otra campana". El trabajo de fundir ambas correría a cargo de uno de los dos maestros contratados. El diámetro de la campana $n^{\circ} 2$ resulta inferior al de la $n^{\circ} 1$, en concreto es de $110 \mathrm{~cm}$, pero a su vez mayor que el de la $n^{\circ} 3$, con un diámetro estimado de $95 \mathrm{~cm}$. Si tenemos en cuenta que fue fundido un esquilón y que el trabajo lo realizó un maestro diferente, el esquilón se correspondería con la campana de menores dimensiones, es decir, la $\mathrm{n}^{\circ}$ 3. Por lo tanto, la fundición del esquilón se produjo en último lugar pero casi de manera simultánea a las dos campanas, manteniendo la unidad en el tiempo, cuando la labor del primer maestro ya había concluido pero 
no habían sido amortizadas las estructuras, ya que el horno fue construido sobre los restos del molde de la campana $n^{0} 1$ (Foto 10). Descartamos que este proceso fuera realizado con carácter posterior, ya que estratigráficamente no hay indicios de reapertura del foso ni de la excavación de nuevas estructuras negativas.

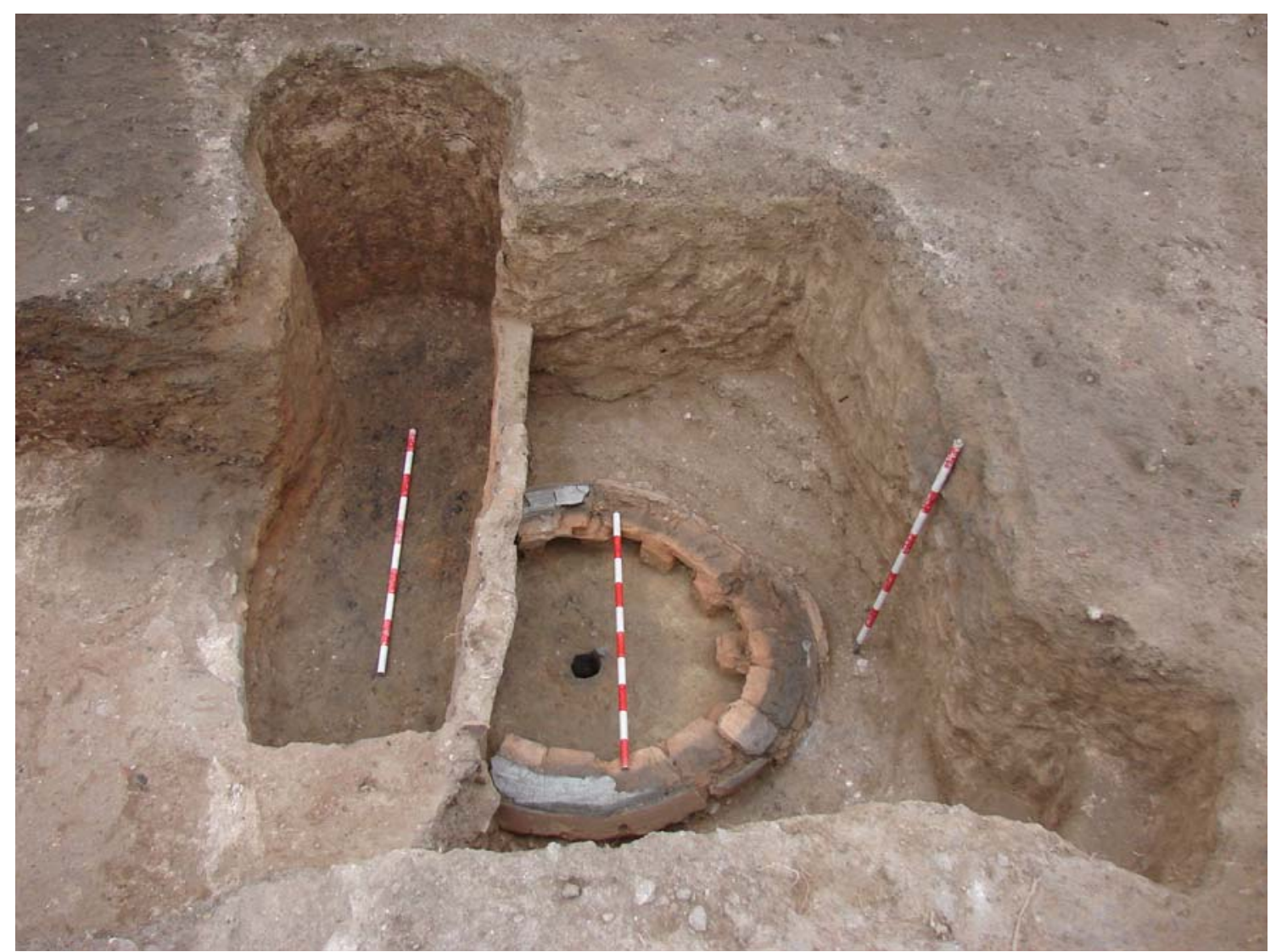

Foto 10: El horno interior fue construido sobre los restos del molde 1

La superposición de actividad también está constatada en el obrador del monasterio leonés de Carracedo, donde en el mismo foso se fundieron cuatro campanas, una después de otra, superponiéndose los restos de los moldes dentro de un mismo proceso de fundición. ${ }^{41}$ En Frandovínez ambos maestros compartieron foso, pero fue diseñado con unas dimensiones perfectamente ajustadas para albergar las tres campanas sin necesidad de recurrir a superposiciones, a excepción de la ubicación del horno interior. Entre el sector central, que acoge a la campana $n^{\circ} 2$, y el sector donde se localiza la campana $n^{\circ} 3(C)$ se construyó un pequeño murete de adobes con la función de formar parte del zócalo del molde de la campana $\mathrm{n}^{\circ} 2$, pero también de

${ }^{41}$ Miguel Hernández, H. 1990: 153. 
compartimentar los sectores $B$ y $C$ reforzando el escalón que media entre ambos.

Una vez listos los moldes se procedió a rellenar (tapear o tabicar) el foso con arena cuidadosamente compactada con el fin de evitar su resquebrajamiento durante la fundición. En la excavación arqueológica el foso apareció colmatado mayoritariamente con esta arena acompañada de algunos materiales cerámicos contemporáneos integrados por lozas y cerámica común vidriada, ${ }^{42}$ mezclada con restos de moldes, trozos de teja y adobes rubefactados procedentes de moldes y hornos. Una vez perfectamente colmatado el foso, se procede a la apertura de la piquera del horno que contiene la colada, y a través de un canal realizado con tejas, troncos de madera vaciados en forma de mediacaña revestidos de barro, o simplemente excavado en el suelo, se conduce a los bebederos de los moldes. En Frandovínez no han sido identificadas evidencias de los canales, pero sí interesantes restos de los dos hornos que participaron en el proceso, lo que aporta un valor añadido al yacimiento, ya que en las excavaciones arqueológicas la documentación de evidencias relacionadas con hornos es muy excepcional, ${ }^{43}$ y por lo general se limitan a posibles restos de solera.

Los hornos de la Vera Cruz son hornos de reverbero en los que se funde el bronce introducido en un crisol mediante la reverberación del calor, que asciende a la bóveda de media esfera inclinada hacia la chimenea y localizada en el extremo opuesto al hogar. Durante el proceso de fusión el horno alcanza una temperatura de $1.00001 .200^{\circ} \mathrm{C}$, y la aleación de cobre/estaño debe ser aproximadamente de 80/20\%, con una merma por la pérdida del 10\%. Durante la excavación ha sido recuperada una moneda de cuatro maravedís de Felipe IV (1652 y 1659) varias veces resellada, localizada en el estrato de amortización y clausura del taller. ${ }^{44}$ Presenta evidencias de exposición al fuego, por lo

42 Este tipo de cerámicas también han sido documentadas entre los sedimentos de relleno del horno de reverbero exterior y en el estrato de nivelación de la superficie, proceso con el que culminó la destrucción del taller. En total pertenecen a 10 recipientes diferentes con la peculiaridad de que fragmentos de una misma pieza aparecen en los tres ámbitos mencionados, lo que pone de manifiesto la contemporaneidad de los procesos de amortización. Se trata de un conjunto cerámico característico del siglo XVIII, con presencia de platos de loza con baño estannífero y fuentes de borde redondeado y fondo anular poco destacado con vidriado jaspeado amarillo y melado.

${ }_{43}$ Marcos Villán, M.A. y Miguel Hernández, F. 1998: 71.

44 Tras la fabricación de las campanas, los materiales constructivos procedentes de los hornos y del foso de colada fueron esparcidos por la superficie de la ermita a modo de acondicionamiento y nivelación aunque de 
que parece que estaba destinada a formar parte de la colada de bronce, lo que finalmente no sucedió. Su presencia posiblemente está relacionada con la tradición de incluir en la aleación monedas (normalmente de oro o plata) con el fin de mejorar el sonido de la campana, aunque de cualquier modo debe entenderse como un material de deshecho al ser una moneda de bajo valor y fuera de circulación.

Según el Libro de Fábrica se trajeron 8 libras de metal de la ciudad de Burgos, compradas a un tal Manuel Linares, lo que supuso un gasto de 5.454 maravedís. El transporte se realizó en carro, y el porte fue aprovechado para traer maromas prestadas por la catedral. ${ }^{45}$

Uno de los hornos documentados se localiza a poco más de medio metro del foso de moldeo y fundición, mientras que el otro fue construido en el interior del foso tras la fundición de las campanas $n^{\circ} 1$ y 2 . La fabricación del primero, el exterior, se llevó a cabo mediante el método tradicional, consistente en la excavación de una fosa sobre la que se asienta la estructura, y que representa la mayor parte de los restos conservados. Tras la excavación se procede a su rellenado mediante arena apisonada, con el fin de mejorar las propiedades refractarias. En Frandovínez este relleno es a base de arena, arcilla tamizada, adobes, trozos de mortero y fragmentos de tejas nuevas. En el proceso se deja sin rellenar parte de un extremo de la fosa, que servirá para la recogida de la ceniza, ya que en este punto aparece localizada la parrilla metálica sobre la que se realiza el fuego.

La fosa de Frandovínez presenta planta ovalada y sección en bañera, y la totalidad de las paredes muestran signos de rubefacción. También han sido identificados restos muy deteriorados del arranque de las paredes de la bóveda y del altillo o escudillo de separación situado entre el crisol y la parrilla, y un espacio semicircular destinado a la colocación de ésta. La suela o solera del crisol, delimitada de la zona de la parrilla por el altillo, es de arcilla tamizada mezclada con fragmentos de leña carbonizada. La chimenea se situaba en el extremo suroriental de la fosa, junto a la puerta de entrada a la ermita.

En el horno documentado en el interior del foso la chimenea se encontraba en el lado opuesto. En este caso no fue necesario excavar la fosa, ya que fue reutilizada una de las estructuras negativas construidas para la fabricación de los moldes de las asas, que sirvió de depósito de cenizas, y el resto de la estructura fue levantada a partir del desnivel o

forma irregular, de manera que en algunas zonas, como en las proximidades de las paredes, es inexistente.

${ }^{45}$ ADB, fol. 2, Libro de Fábrica de la iglesia parroquial de San Miguel, 1788-1859. 
escalón geológico de separación de los sectores A y B o construido con adobe (Foto 11). De este horno no se conservan restos del arranque de la bóveda pero sí de la suela dispuesta sobre el relleno de colmatación, ambos similares a los descritos para el horno exterior. Como también sucede en aquel, el depósito de cenizas apareció relleno con los restos de la quema de leña y pequeños fragmentos de bronce procedentes de la colada.

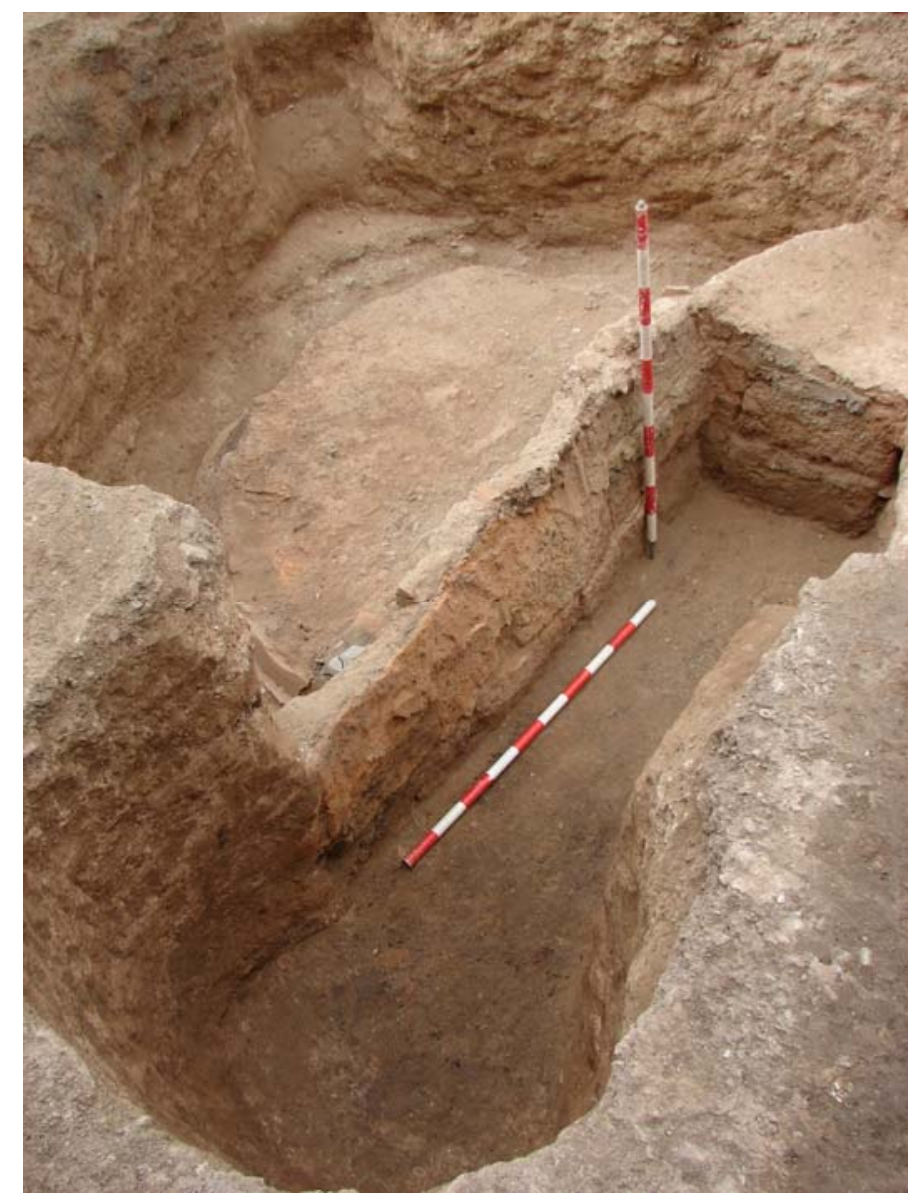

Foto11: El horno interior fue construido parcialmente con adobes, y aprovechó una de las fosas laterales para hogar

Una vez que la colada ha sido introducida en los moldes éstos se dejan enfriar lentamente, proceso que puede durar dos días. Tras el enfriamiento y la retirada del relleno del foso, se rompe la capa de los moldes y finalmente se vuelcan las campanas para liberarlas del macho.

En Frandovínez el traslado de las campanas hasta la iglesia de San Miguel y su subida a la torre se realizó con la ayuda vecinal, tal y como figura en el Libro de Fábrica, donde se anotaron 26 maravedís en 
concepto del refresco con el que se obsequió a los participantes. En la totalidad del proceso colaboraron otros oficios y artesanos además de los campaneros, relacionados con el transporte de la madera y el hierro con los que se fabricaron las diferentes piezas necesarias para "enejar, (...) $\operatorname{armar}(. .$.$) y poner en perfección"46 las campanas.$

Terminado todo el proceso fueron destruidos los hornos y demás estructuras situadas por encima del nivel del suelo, y un cantero retejó y allanó el edificio para devolverle su función de ermita. Los maestros campaneros realizaban este proceso de destrucción también con la finalidad de preservar los secretos del oficio; de hecho, toda la actividad se solía realizar a puerta cerrada y las diferentes técnicas se transmitían de padres a hijos.

\section{CONCLUSIONES}

El taller de fundición de campanas de 1788 documentado mediante excavación arqueológica en el solar de la antigua ermita de la Vera Cruz, surgió como consecuencia de una necesidad puntual y concreta: la de fabricar una nueva campana y un esquilón para la iglesia parroquial de San Miguel. Por este motivo, el trabajo corrió a cargo de campaneros itinerantes "a pie de obra". Aunque no existen datos sobre su identidad u origen, es posible que procediesen del norte peninsular, donde tradicionalmente los secretos de este trabajo artesanal han pasado de padres a hijos a lo largo de generaciones. El taller de Frandovínez fue compartido por dos maestros diferentes, y mediante la excavación arqueológica se ha comprobado que fueron tres y no dos, como figura en el libro de fábrica de la iglesia parroquial, las campanas realizadas. El gasto apuntado, sin embargo, únicamente hace alusión a una campana y a un esquilón, con una suma total de 8.640 maravedís. También existe relación detallada del desglose económico de la obra, en la que no sólo estuvieron implicados los campaneros, sino también canteros, carpinteros, herreros, carreteros y, finalmente, los vecinos de Frandovínez que subieron las nuevas campanas a la torre.

La intervención arqueológica ha supuesto una oportunidad excepcional para documentar en su totalidad las estructuras integrantes de un obrador que utilizó los procedimientos tradicionales de fabricación habituales de la Edad Moderna, y que se mantuvieron prácticamente sin variaciones hasta la Edad Contemporánea.

Las actuales campanas de la iglesia de San Miguel fueron realizadas en el siglo XX, el esquilón en 1929 y las tres campanas en

${ }^{46}$ Ídem. 
1966, de modo que no se conservan las fundidas en el obrador de la Vera Cruz.

\section{BIBLIOGRAFÍA}

Aguirre Sorondo, A. 1997. "La fundición de campanas", en E. Gómez Pellón y J. Guerrero Carot (coords.), Las campanas: cultura de un sonido milenario: 479-496. Santander: Actas del I Congreso Nacional sobre Campanas. Fundación Marcelino Botín.

Alonso Ponga, J.L. y Sánchez del Barrio, A. 1997. La Campana. Patrimonio sonoro y lenguaje tradicional. La Colección Quintana en Urueña. Valladolid: Fundación Joaquín Díaz.

Barrio Loza, J. 1997. "La campanería de Bizkaia (siglos XVI-XIX). La competencia entre fundidores 'vizcainos' y montañeses", en E. Gómez Pellón y J. Guerrero Carot (coords.), Las campanas: cultura de un sonido milenario: 113-132. Santander: Actas del I Congreso Nacional sobre Campanas. Fundación Marcelino Botín.

Gonzalo Gozalo, A. 2007. Frandovínez: más de mil años. Salamanca: Pueblos de Burgos.

Gonzalo Gozalo, A. 2011. "Desde la experiencia. El clero de Burgos ante la invasión francesa", en C. Borreguero Beltrán (coord.), La Guerra de la Independencia en el Mosaico Peninsular (1808-1814): 673693. Burgos: Universidad de Burgos.

Hervás Herrera, M.A. 2010. "El foso de fundición de campanas de la ermita de San Francisco -siglo XVIII- (Tomelloso, Ciudad Real). Boletín Arqueológico Medieval 14: 93-127.

Madoz, P. 1850. Diccionario geográfico-estadístico-histórico de España y sus posesiones de ultramar, volumen VIII, Madrid.

Marcos Villán, M.A. y Miguel Hernández, F. 1998. Maestros campaneros, campanas y su fabricación en Valladolid y su provincia (Siglos XVI a XVIII), Valladolid: Diputación Provincial de Valladolid.

Miguel Hernández, H. 1990. "Testimonio arqueológico de una actividad artesanal: la fundición de campanas en el Monasterio de Carracedo (León)", Bierzo. Milenario del Monasterio de Carracedo: 145162. León: Basílica Nuestra Señora de la Virgen de la Encina. 
Miguel Hernández, H. y Marcos Villán, M.A. 1997. "Arqueología del horno de fundición de campanas del convento de San Francisco Extraportem de Zamora", en E. Gómez Pellón y J. Guerrero Carot (coords.). Las campanas: cultura de un sonido milenario: 439-456. Santander: Actas del I Congreso Nacional sobre Campanas. Fundación Marcelino Botín.

Navarro Espinach, G. 2006. "Las cofradías de la Vera Cruz y de la Sangre de Cristo en la corona de Aragón (siglos XIV-XVI)". Anuario de Estudios Medievales 36: 583-611.

Padilla, J.I. y Vives i Balmaña, E. 1983. "Les excavacions a l'eclésia de Sant Andreu (Orrius)", Excavacions Arqueològiques a Catalunya 2: 51-55. Barcelona, Departamento de Cultura de la Generalitat de Catalunya.

Palacios Sanz, J.I. 2010: "Campanas góticas de Castilla y León. Un patrimonio sonoro". Acta Histórica et Archaeologica Medievalia 30: 411451.

Sánchez Herrero, J. 1999. "Las cofradías de Semana Santa de Sevilla durante la modernidad", en R. Sánchez Mantero (coord.). Las Cofradías de Sevilla en la Modernidad.: 27-98. Sevilla: Universidad de Sevilla.

Sánchez-Monje, M. y Viñé Escartín, A.I. 1993. "Excavación arqueológica en el solar de la plaza Arias Gonzalo (Zamora)". Nvmantia 4: 263-280.

Viñé Escartín, A.I., Salvador Velasco, M. y Larrén Izquierdo, Hortensia. 1999. "La iglesia románica de Santo Tomé de Zamora y las estructuras excavadas en su entorno", Nvmantia 7: 149-162. 